Portland State University

PDXScholar

Summer 7-26-2016

\title{
Teacher Mindfulness in the Middle School \\ Classroom: Reliability and Validity of a New Scale
}

Nicolette Paige Rickert

Portland State University

Follow this and additional works at: https://pdxscholar.library.pdx.edu/open_access_etds

Part of the Junior High, Intermediate, Middle School Education and Teaching Commons, and the Psychology Commons

Let us know how access to this document benefits you.

\section{Recommended Citation}

Rickert, Nicolette Paige, "Teacher Mindfulness in the Middle School Classroom: Reliability and Validity of a New Scale" (2016). Dissertations and Theses. Paper 3118.

https://doi.org/10.15760/etd.3114

This Thesis is brought to you for free and open access. It has been accepted for inclusion in Dissertations and Theses by an authorized administrator of PDXScholar. Please contact us if we can make this document more accessible: pdxscholar@pdx.edu. 
Teacher Mindfulness in the Middle School Classroom:

Reliability and Validity of a New Scale

by

Nicolette Paige Rickert

A thesis submitted in partial fulfillment of the requirements for the degree of

\author{
Master of Science \\ in \\ Psychology
}

Thesis Committee:

Robert Roeser, Chair

Ellen Skinner

Andrew Mashburn

Joel Steele

Portland State University

2016 
Abstract

Despite significant growth in research examining the effects of mindfulness interventions on teachers (Roeser, 2014), studies have mainly relied on self-reports of teacher mindfulness and have not examined observable behavioral manifestations of teacher mindfulness in the classroom. Due to possible biases in self-report measures (Dotterer \& Lowe, 2011), as well as the need for a greater range of assessments of the effects of mindfulness trainings on teachers, the current study sought to create a new measure of teacher mindfulness in the classroom from three sources of information: teacher self-reports of their own behavior in the classroom, student perceptions of their teachers' behavior, and third-person observations of teacher behavior in the classroom. Another aim of this study was to demonstrate the concurrent validity of these new measures with teacher dispositional mindfulness and job stress. It was hypothesized that the newly created measures of teacher mindfulness in the classroom would be internally reliable, share modest inter-correlations across data sources, and would significantly correlate with hypothesized antecedents such as teachers' dispositional mindfulness and ratings of job stress. CFA, correlation, and regression analyses found good internal consistencies for each informant source of teacher calmness, clarity, and kindness; partial support for the convergent validity of each informant source; and partial concurrent validity only for teacher reports of mindfulness in the classroom with teachers' dispositional mindfulness and job stress. Evidence of method effects was suggested from these analyses. The future use, re-configuration, and implications of this suite of measures are discussed. 
I would like to thank the William T. Grant Foundation, Spencer Foundation, and Portland State University for making this research possible. I would also like to acknowledge the help and cooperation of the district and participating teachers, the CaCiEL research team, my committee, and my advisor, Dr. Rob Roeser. Finally, I want to thank my parents, Mark and Susan Rickert, my brother, Joshua Rickert, and my partner, Jordan Futran, for always supporting me in all my endeavors. Thank you so much for your confidence and love. 


\section{Title}

Abstract.

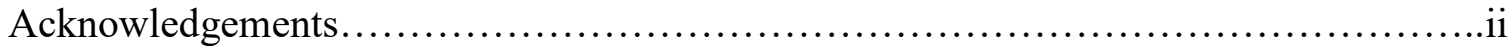

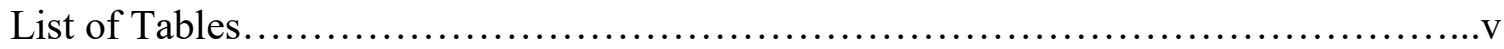

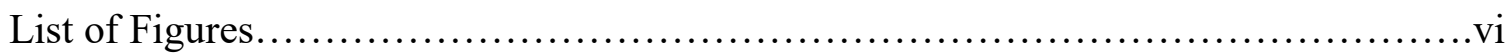

Chapter One: Problem Statement.......................................................

Theoretical Framework................................................... 2

Historical Background for Conceptualizing Teacher Mindfulness in the Classroom................................................... 4

Mindfulness as Calm, Clear, and Kind................................. 6

Chapter Two: Study Aims and Research Questions................................... 8

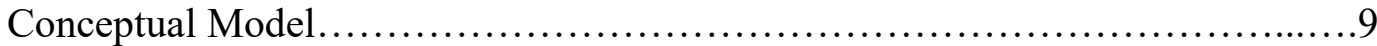

Research Question 1..................................................... 9

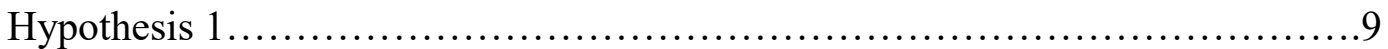

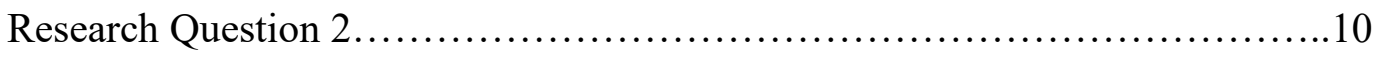

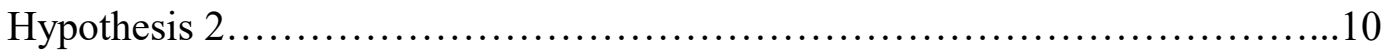

Chapter Three: Literature Review.............................................. 11

Beyond Psychological Measures of Mindfulness in Teacher Studies..............11

The Measurement of Teacher Behavior and Classroom Environments............15

Summary of Current Study................................................ 18

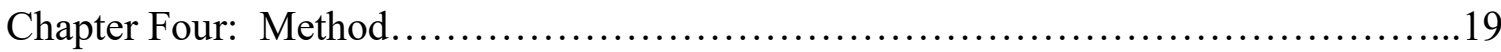

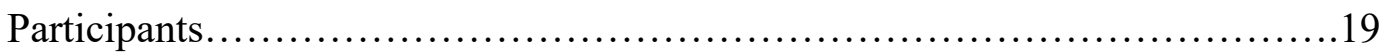

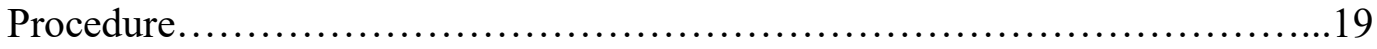

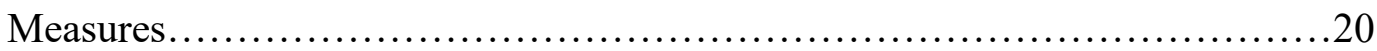

Teacher Mindfulness..................................................

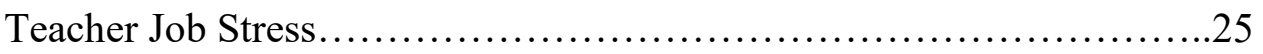

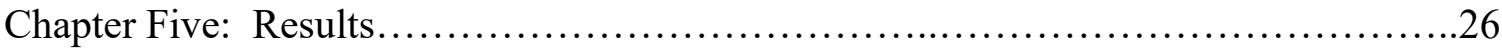

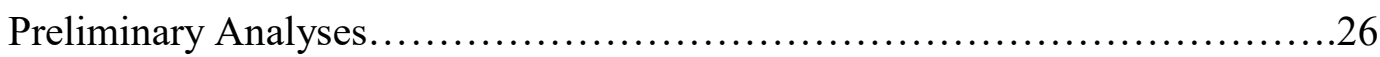

Item Selection and Reduction...................................26

Confirmatory Analyses for Retained Items in Single Models..............28

Creating Composite Scales Across Informants..........................33

Testing the Reliability and Validity of Teacher Mindfulness in the Classroom....33

Teacher Mindfulness in the Classroom, Dispositional Mindfulness, and Job

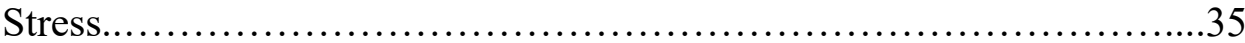

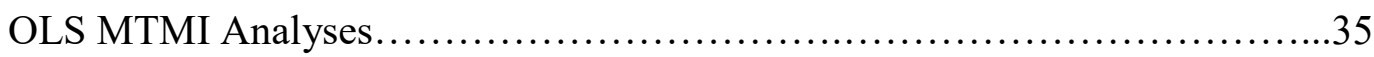

OLS Concurrent Validity Analyses.........................................

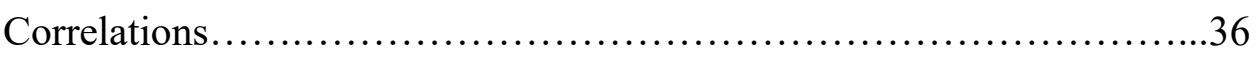

Regression Analyses................................................... 
TEACHER MINDFULNESS IN THE CLASSROOM iv

Chapter Six: Discussion................................................... 38

Summary and Explanation of Findings.................................... 38

Limitations and Future Directions......................................41

Implications.................................................... 34

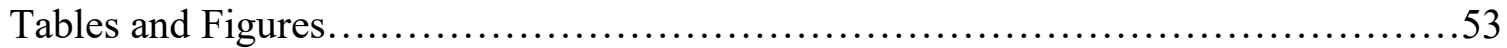

References.................................................................. 84

Appendix A. Literature Review Article Tables........................................92

Appendix B. Measures........................................................ 99 
Table 1. Definitions of Calm, Clear, Kind, and Antitheses.

Table 2. Behavioral Indicators from the CLASS-S for Teacher Mindfulness in the

Classroom.............................................................. 47

Table 3. Descriptive Statistics for all Selected Items from Each Informant Source.......49

Table 4. Standardized Residuals for 6-Factor Teacher Report CFA.....................54

Table 5. Standardized Residuals for 3-Factor Teacher Report CFA......................56

Table 6. Chi-Square Difference Test of 6- vs. 3-Factor Teacher Report CFAs...........57

Table 7. Standardized Residuals for 1-Factor Teacher Report CFA....................59

Table 8. Chi-Square Difference Test for 3- vs. 1-Factor Teacher Report CFAs...........60

Table 9. Standardized Residuals for 3-Factor Student Report CFA.....................63

Table 10. Standardized Residuals for 1-Factor Student Report CFA...................65

Table 11. Chi-Square Difference Test for Student Report CFAs.......................66

Table 12. Standardized Residuals for 3-Factor Observer Report CFA..................69

Table 13. Standardized Residuals for 1-Factor Observer Report CFA.................71

Table 14. Chi-Square Difference Test for Observer Report CFAs....................72

Table 15. Descriptive Statistics for Composite Variables of Calm, Clear, and Kind from

Each Informant Source...............................................73

Table 16. Standardized Residuals for Calm, Clear, and Kind CFA.....................76

Table 17. Standardized Residuals for Teacher, Observer, and Student CFA..............78

Table 18. MTMI Matrix for Calm, Clear, and Kind from Teacher, Observer, and Student Reports...................................................79

Table 19. Correlations Between Each Teacher Mindfulness in the Classroom Measure and Teacher Dispositional Mindfulness and Job Stress.....................80

Table 20. Regression Analyses Predicting Teacher Reports of Calm, Clear, and Kind...81 Table 21. Regression Analyses Predicting Observer Reports of Calm, Clear, and Kind..82 Table 22. Regression Analyses Predicting Student Reports of Calm, Clear, and Kind...83 


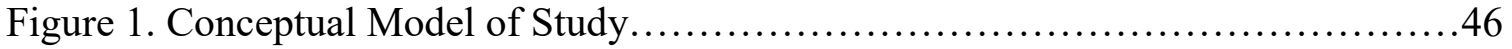

Figure 2. Proposed 6-Factor CFA Model for Teacher Reports........................52

Figure 3. CFA 6-Factor Model for Teacher Reports.................................53

Figure 4. CFA 3-Factor Model for Teacher Reports..................................55

Figure 5. CFA 1-Factor Alternative Model for Teacher Reports.......................58

Figure 6. Proposed CFA Model for Student Reports................................61

Figure 7. CFA Model for Student Reports......................................62

Figure 8. CFA 1-Factor Alternative Model for Student Reports.......................64

Figure 9. Proposed CFA Model for Observer Reports.............................67

Figure 10. CFA Model for Observer Reports....................................68

Figure 11. CFA 1-Factor Alternative Model for Observer Reports..................... 70

Figure 12. Proposed MTMI CFA model........................................ 74

Figure 13. Calm, Clear, Kind CFA Model from Each Informant......................75

Figure 14. Method Effects CFA Model........................................77 
TEACHER MINDFULNESS IN THE CLASSROOM

Chapter One

\section{Problem Statement}

Recently, there has been a rise in the number of studies examining mindfulness training for teachers and students within the school context in an effort to transform the culture of education (Ergas, 2015) and to improve teaching and learning (Roeser, 2014). While Roeser (2014) found that a Google web search of the word "mindfulness" yielded over 5 million results in 2014, that number has increased to over 39 million in just two years (May, 2016). Recent studies have shown that mindfulness training can cultivate changes in teachers' perceptions of their mindfulness and attention regulation, as well as reductions in job stress and burnout (e.g., Flook et al., 2013, Roeser et al., 2013).

With the rapid spread of a new research topic comes the need for new measures as well. To date, most studies have examined teacher mindfulness and programs to cultivate it using self-report questionnaires ranging from the Five Factor Mindfulness Questionnaire (FFMQ; Baer et al., 2006; Baer et al., 2008) that identifies five key sub facets of mindfulness; to the Mindful Attention Awareness Scale (MAAS; Brown \& Ryan, 2003) that measures mindlessness and reverse codes items; to the Interpersonal Mindfulness in Teaching Questionnaire (IMT; Frank, Jennings, \& Greenberg, 2016; Greenberg, Jennings, \& Goodman, 2010) that focuses on the behaviors and emotions of teachers while teaching. With the exception of the IMT, these measures are not situated in the classroom context (i.e., focused on the specific classroom environment in which a teacher teaches). Beyond the lack of situated measures, it is also the case that self-report measures are susceptible to certain limitations: common method bias and socially desirable responding (Dotterer \& Lowe, 2011). The issue of socially desirable responding 
is especially important in the context of mindfulness training interventions in which teachers know that changes in personal mindfulness are an explicit goal of the program and the research on the program (Davidson \& Kaszniak, 2015; Grossman \& Van Dam, 2011). Therefore, it is important to develop new reliable and valid measures of mindfulness that address these potential limitations of context-independent, self-report measures.

In this study, I focus on measuring naturalistically occurring mindful teacher behaviors in the classroom from three different perspectives: those that represent firstperson, second-person, and third-person measures. Specifically, the purpose of this thesis is to examine the attributes of a new, multi-concept multi-informant measure of teacher mindfulness in the classroom, and thereby, to move science forward with regard to gaining a better understanding of what mindful teaching looks like and how mindfulness trainings for teachers can be assessed with regard to hypothesized, observable changes in teacher mindfulness in the classroom. New measures of teacher mindful behavior in the classroom might also lead to new insights into the hypothesized antecedents (e.g., teacher dispositional mindfulness, job stress) of such behaviors (e.g., Roeser, 2016a; 2016b).

\section{Theoretical Framework}

This thesis and its constituent research questions and hypotheses extend beyond the current theoretical frameworks that focus on mindfulness from neurobiological and psychological perspectives that view it as a state or trait, an individual difference variable and a skill that is educable (e.g., Brown \& Ryan, 2003; Davidson \& Kaszniak, 2015; Lutz, Jha, Dunne, \& Saron, 2015). Within these diverse approaches, it is clear that no one consensual view or definition of mindfulness exists (Lutz et al., 2015). Many studies 
draw upon a previous definition offered by Jon Kabat-Zinn in which mindfulness is described as "paying attention in a particular way: on purpose in the present moment, and nonjudgmentally" (Kabat-Zinn, 1994, p.4). Others draw on definitions offered by Shinzen Young who defined mindfulness as a threefold attentional skillset involving concentration, the ability to focus on what you want to focus on when you want to focus on it; clarity, "the ability to keep track of components of your sensory experience as they arise in various combinations, moment-by-moment;" and equanimity, "an attitude of gentle matter-of-factness with regard to your sensory experience” (Young, 2006, p.2). Other studies have used similar terms to mindfulness. Rodgers and Raider-Roth (2006, p.266), for instance, defined "presence" as "a state of alert awareness, receptivity, and connectedness to the mental, emotional, and physical workings of both the individual and the group in the context of their learning environments, and the ability to respond with a considered and compassionate best next step."

These definitions all focus on a phenomenological, psychological definition of mindfulness that is personal and private. In this thesis, in contrast, I am interested in examining behavioral manifestations of mindfulness in the specific setting of the classroom context. In order to come to this conceptualization of mindfulness in behavioral and potentially observable terms, I draw on the work and consensus of experts on contemplation in education at a series of meetings from the Mind and Life Educational Research Network and related meetings at the Garrison Institute in New York as well as the operationalization of this conceptualization of teacher mindfulness in the classroom in new measures in a mindfulness training study for middle school teachers at Portland State University (Roeser, Mashburn, \& Skinner, 2014). 
Historical background for conceptualizing teacher mindfulness in the

classroom. The ideas that formed the conceptual framework for this thesis emerged out of inter-disciplinary dialogues between contemplative practitioners and scholars working with the Mind and Life Institute and the Garrison Institute in their efforts to catalyze the science practice around secular contemplative practices in American education.

The Mind and Life Institute (MLI) is a non-profit organization dedicated to the integration of science, contemplative practices, and wisdom traditions with the aims of alleviating suffering and cultivating flourishing. MLI has been a leader in the development of the fields of Contemplative Neuroscience, Contemplative Clinical Science, and Contemplative Education (see https://www.mindandlife.org). In 2006, donations made it possible to create the Mind and Life Educational Research Network (MLERN; see Mind and Life Institute, 2009). The goals of the network were to bring together practitioners, scientists, and educators from all over the country to educate the group on the current state of affairs by (a) identifying promising programs for secularized contemplative practices in education; (b) examining existing measures for program evaluation and stimulating research on the development of new measures for us in research on contemplative practices in education; and (c) creating a scientific framework that could inform future research (see Mind and Life Institute, 2009). The network was chaired by Richard Davidson and ran for three years (2006-2009). Dr. Robert Roeser was a member of the network, and reports that at an MLERN meeting in 2006 at Wellesley College, author and psychologist Daniel Goleman suggested that those who embody the fruits of engaging in contemplative practices might be cogently described as "calm in 
body, clear in mind, kind in heart" (R.W. Roeser, personal communication, June 18, 2016).

This conceptual notion was explored in relation to observation measures of teachers and teaching at a meeting of the Garrison Institute in 2009. The meeting, entitled "Exploring Methodological Issues in Contemplative Education Research: A Focus on Teachers" was chaired by Patricia Jennings and Mark Greenberg, members of the leadership council of the Garrison Institute's educational work. The Garrison Institute is a non-profit organization dedicated to supporting work that grounds social action in the wisdom of contemplation in order to build a more compassionate and resilient future, and has been a leader and partner with MLI in the area of Contemplative Education (see Schoeberlein \& Koffler, 2005). The focus of the 2009 meeting was to explore potential outcome measures of teacher mindfulness training beyond those employing self-reports (e.g., observations, biomarkers, experience sampling, etc.). A major outcome of this meeting after extended discussion and watching videotapes of teachers was that the Classroom Assessment Scoring System observational measure might already have the kinds of behaviors that would be most likely to change due to a mindfulness intervention for teachers, especially in the domains of emotional support and classroom organization (Pianta \& Hamre, 2009). Thus, those working with programs with teachers, including the MPower teacher mindfulness program (Cullen \& Pons, 2015) used in this project and thesis, agreed to employ this measure in future research projects.

Given the fruits of these previous meetings on measures of the effects of contemplative trainings on teachers, the current study conceptualizes and measures mindfulness in a situated dispositional manner, in relation to three embodied qualities of 
what teacher mindfulness would look like in the classroom context: calmness in body and mind (e.g., emotionally regulated); clarity in awareness, word, and deed (e.g., aware of what is happening, clear expectations); and kindness in relationships with others (e.g., empathetic to, forgiving of, and compassionate toward self and others; see Table 1 for definitions). In addition, use of the Classroom Assessment Scoring System is employed, partly, to capture measures of these three qualities through non-self-report measures.

Mindfulness as calm, clear, and kind. Previous definitions of mindfulness support Dan Goleman's notion of mindful individuals demonstrating calmness, clarity, and kindness. Because mindfulness involves equanimity (Young, 2006), receptivity (Rodgers \& Raider-Roth, 2006), and acceptance, it is linked to the notion of emotional balance and calmness. Thus, mindful teachers should be calm, stable, and emotionally regulated in the classroom in the face of challenges. Being mindful also incorporates paying attention (Kabat-Zinn, 1994) and being alert and aware (Rodgers \& Raider-Roth, 2006) of moment-to-moment experience (Young, 2006), which is linked to the notion of being clear in thought, word, and deed. In theory, mindful teachers should be focused and fully present in the classroom and set clear expectations for their students. Finally, mindfulness is defined as being nonjudgmental (Kabat-Zinn, 1994; Young, 2006), connected, and compassionate (Rodgers \& Raider-Roth, 2006), which denotes the dimension of kindness. For teachers, mindfulness should include perspective-taking and being empathic in their interactions with their students. Thus, based on previous definitions of mindfulness, logical analysis, and previous scholarly meetings, I use a definition of teacher mindfulness in the classroom in which notions of calm, clear, and kind behaviors are central. 
In addition to these three key elements of teacher mindfulness, I introduce their

theoretical antitheses (see Table 1 for definitions). Thus, a lack of calmness would suggest reactivity or emotional imbalance and rumination. A lack of clarity would involve distraction or confused and chaotic awareness, word, and deed. Finally, a lack of kindness suggests being critical or blaming others and focusing on the self. In this thesis, I propose to measure the three key aspects of teacher mindfulness in the classroom (calm, clear, kind) combined with their reverse-coded antitheses (reactive, distracted, critical). 
TEACHER MINDFULNESS IN THE CLASSROOM

Chapter Two

\section{Study Aims and Research Questions}

The aims of this research study are to create a new reliable and valid measure of teacher mindfulness in the classroom that is context-dependent and addresses the potential limitations of self-report measures; as well as to examine the relation of teacher mindfulness in the classroom to teachers' dispositional mindfulness and job stress.

Currently, there is a dearth of research that assesses teacher mindfulness in the classroom, or that does so from multiple sources of data (first-person, second-person, third-person reports). As such, a main goal of the proposed study is to examine the validity and reliability of a new measure of teacher mindfulness in the classroom (derived from teacher self-reports, students' second-person perceptions, and third-person researcher observations of the teacher in the classroom). In addition, this study examines the concurrent validity of these new measures of teachers' classroom mindfulness in relation to teacher dispositional mindfulness and job stress (see Jennings \& Greenberg, 2009;

Roeser, Skinner, Beers, \& Jennings, 2012).

With regard to concurrent validity, based on previous research, I hypothesize that teachers who are more mindful will be less stressed (Jennings, Snowberg, Coccia, \& Greenberg, 2011; Nezlek, Holas, Rusanowska, \& Krejtz, 2015; Prakash, Hussain, \& Schirda, 2015; Short, Mazmanian, Oinonen, Mushquash, 2015). Greater mindfulness and less stress hypothetically allow teachers to be calmer in the classroom. This in turn, affords a greater possibility that they can view their students and classroom with greater clarity. Less stress also may afford teachers greater resources to address student needs and invest in emotionally supportive, kind relationships with students (e.g., Roeser et al., 
2012). Thus, it is hypothesized that teachers who have higher levels of dispositional mindfulness and lower job stress will score higher on a new measure of teacher mindfulness in the classroom.

\section{Conceptual Model}

Figure 1 depicts the proposed conceptual model of this study in which teachers' calmness, clarity, and kindness (as derived from self-reports, students' perceptions, and third-person observations of teacher mindfulness in the classroom) are each related to one another. Teacher dispositional mindfulness and job stress are proposed as antecedents to teacher mindfulness in the classroom. Teacher mindfulness in the classroom is proposed to be positively related to dispositional mindfulness and negatively with teachers' job stress. Although dispositional mindfulness and job stress are proposed as antecedents, due to a lack of longitudinal data in this proposed study, these predictive relations cannot be tested. Rather, these relations will be examined through concurrent associations in this report.

To summarize, the study addresses the following research questions and related hypotheses:

Research Question 1. Can teacher mindfulness in the classroom be reliably and validly measured from sources that include, but go beyond, self-report measures?

Hypothesis 1. Teachers' self-report measures of their own mindfulness, students' perceptions of mindful teachers, and third-person observations of teachers' mindful behaviors will all be positively and significantly related to one another and will combine to form a reliable measure of teachers' capacity to be calm, clear, and kind in the classroom. 
Research Question 2. Is the new measure of teacher mindfulness valid with concern to postulated antecedents (teacher dispositional mindfulness, teacher job stress)?

Hypothesis 2. Each of the three teacher mindfulness aspects of being calm, clear, and kind (each created from teacher self-reports, student perceptions, and third-person observations) will be significantly related to teachers' dispositional mindfulness (positively) and job stress (negatively).

Given these research questions and the proposed conceptual model (see Figure 1), the next section examines studies of teacher mindfulness and the ways that mindfulness is measured in these studies. This section includes a critique of this work in that it relies exclusively on self-report measures of teachers' dispositional mindfulness and highlights the need for developing behavioral and observational measures of teacher mindfulness in the classroom (e.g., Jennings et al., 2013). In order to provide a context for creating such a new measure, I review selected research on teacher behaviors and classroom climate, and the importance of third-person observations in the study of teacher behavior and classroom climate. This section ends with a proposal that existing measures of teacher behaviors and classroom climate already index relevant observable behaviors of calmness, clarity, and kindness. 
Chapter Three

\section{Literature Review}

\section{Beyond Psychological Measures of Mindfulness in Teacher Studies}

Previous research on mindfulness has focused on its relation with various aspects of adults' lives. Studies examining dispositional mindfulness in adults have discovered that higher levels of dispositional mindfulness are related to improvements in stress, health, and well-being (Brown \& Ryan, 2003; Hanley, Warner, \& Garland, 2015; Nezlek et al., 2015; Prakash et al., 2015; Short et al., 2015). Recently, the number of studies investigating the effects of mindfulness training for teachers has been growing. Table A in Appendix A presents a short summary of these recent studies looking at mindfulness in teachers and adults in general, including the sample, design, effects, and how mindfulness was measured. As shown in Table A, most of the work on mindfulness with teachers has involved randomized control trials. These studies have found causal links between mindfulness training for teachers and teachers' self-reports of increased mindfulness, reduced stress, reduced work burnout, and improvements in self-regulation measured in various ways (Flook et al., 2013; Jennings et al., 2011; Roeser et al., 2012; Roeser et al., 2013; Taylor et al., 2016).

Of note from Table A, each reviewed study that measured mindfulness did so with a self-report measure, including the FFMQ (Baer et al., 2006; Baer et al., 2008), the MAAS (Brown \& Ryan, 2003), or the IMT (Frank et al., 2016; Greenberg et al., 2010). The FFMQ measures five aspects of mindfulness: observing, describing, acting with awareness, non-judgment of inner experience, and nonreactivity to inner experience. The MAAS uses reverse-coded mindlessness items to measure dispositional mindfulness. The 
IMT assesses how teachers are mindful in their behaviors and emotions while they are teaching and interacting with their students. Some studies have examined relations between such measures and other training related data or observations of behavior in the classroom. Roeser (2016a), for instance, found that most of a program's content taught the five facets of mindfulness as articulated by Baer et al. (2006) and that teachers reported pre/post changes in self-reports of these five skills and self-compassion. Though a case study, and not a causal one, this study suggests that content analyses of what programs aim to teach teachers and what teachers report learning based on self-report mindfulness scales might be aptly suited for one another.

Jennings (2014) examined the concurrent relation between teachers' dispositional mindfulness and observations of their classrooms. It was found that teachers with higher levels of dispositional mindfulness had more emotionally supportive classrooms, were more likely to perspective-take, and had a higher sensitivity of discipline (i.e., proactive rather than reactive management strategies) than teachers with lower levels of dispositional mindfulness. Thus, when studying the effects of mindfulness training on teachers, or individual differences in teacher mindfulness, it is important to examine teachers' embodiment of mindfulness in the classroom. Furthermore, it appears that teachers' mindful dispositions are likely to relate to their mindful behaviors in the classroom - something I explore anew in this study.

While these studies show teacher self-report measurements of mindfulness may have plausible antecedents and consequences, and other work has shown their general good internal reliability (FFMQ: $\alpha=.72-.92$ for each facet; Baer et al., 2006; MAAS: $\alpha$ $=.80-.87$ across samples; Brown \& Ryan, 2003; IMT: $\alpha=.71$; Frank et al., 2016), they 
may nonetheless be subject to various content-based and methodological biases

(Grossman, 2011; Grossman \& Van Dam, 2011). In a critique of self-report mindfulness measures, Grossman (2011) discusses how these self-report measures are problematic due to a lack of convergent validity with other measures of mindfulness, response biases (especially with previous mindfulness practice), a lack of clear external referents to define what a mindful person is, a lack of content validity (e.g., how much the measure actually measures all aspects of mindfulness), and specifically with the MAAS, the question of whether or not individuals can really accurately assess their own mindlessness (i.e., inattention). Relevant to this thesis, the need for observable, behavioral manifestations of mindfulness in specific settings is needed, and may serve the useful function of anchoring self-report measures to observable referents with real-world consequences (e.g., greater behavioral regulation of affect or mental clarity in the classroom).

Thus, as has been suggested by Roeser and Eccles (2015) and Jennings (2014), new work needs to determine how to validly and reliably measure mindfulness with methods beyond self-reports given that such measures can often be biased by common method bias and socially desirable responses (Dotterer \& Lowe, 2011). While some of these previous studies do employ third-person measures of attention regulation, working memory capacity, and executive function (e.g., Roeser et al., 2013), most used the same method for measuring predictor and outcome variables (self-report), possibly resulting in common method bias with regard to results. In addition, participant responses on selfreport measures might in part be impacted by their knowledge that they will be or are participating in a mindfulness intervention study, especially since most of these studies 
did not blind participants to their group assignment or the fact that the studies were interested in mindfulness (Davidson \& Kaszniak, 2015). Thus, the mindfulness measure may be more salient than other measurement items to participants since they are aware that they are participating in an intervention on mindfulness. Participants might even change their responses (consciously or unconsciously) in the hopes of demonstrating an effect or change as a result of the intervention (Grossman \& Van Dam, 2011). Thus, while self-report measures are effective in gathering data on internal processes and dispositions, they do have certain biases that can limit how well they are measuring the construct of interest. Rather than using only first-person measures, second- and thirdperson measures of individuals' mindful behavior in life should also be included in future research to offset these potential limitations.

However, few studies employ measures of mindful behavior in everyday life from multiple informant sources, and this seems a particular weakness of the research on teachers, where changing embodied behavior in the classroom has been posited as a key hypothesized outcome of mindfulness training for teachers (e.g., Roeser et al., 2012). For example, as active participants in the classroom environment, students' reports of their teachers' mindful behaviors can be fruitfully included in measurements of teacher mindfulness in addition to observational measurements by third-person, objective raters. Such multi-informant reports could give a more nuanced and less biased view of what teacher mindfulness really looks like in the classroom environment than the more limited view that self-reports afford. While student reports may be biased by students' developmental stage and specific relationships with a teacher, they are still active participants in the classroom environment each day and therefore "expert" observers of 
their teacher and classroom. In addition, although third-person observers lack the history of relationships between students and teachers, they are also more objective raters of the immediate classroom environment. By combining self-reports, student perceptions, and third-person observations, the limitations of each informant source can be addressed by the strengths of another.

In sum, there is a dearth of research examining mindfulness in the everyday embodied behavior of adults, specifically teachers, from second- or third-person reports and observations. Research on measuring teacher behavior and classroom climates provides an important line of work for informing the construction of a new measure of teacher mindfulness in the classroom. An important next step for research on mindfulness would be to incorporate self-reports, student perceptions, and third-person observations in order to fully measure teachers' situated dispositional mindfulness in the classroom environment, both inwardly and outwardly.

\section{The Measurement of Teacher Behavior and Classroom Environments}

Various studies have examined multi-informant reports of teachers and classroom climates. For instance, in one study, Wang and Eccles (2014) studied math classroom climates using both teacher and student perceptions of the classroom. They discovered that teachers and students had significant agreement on perceptions of collaboration promotion and autonomy support in the classroom, but non-significant agreement for authentic instruction and teacher social support. These correlations between teacher and student reports were small, suggesting that each has a different, subjective perception of the classroom climate. Thus, third-person, unbiased perceptions of classroom climates are 
needed to anchor these two subjective reports from active participants with a more objective one from observers.

Several observational measures of teacher behaviors and classroom climates exist (e.g., Early Childhood Environment Rating Scale, Harms, Clifford, \& Cryer, 2014; Classroom Observation System, Pianta et al., 2002; Early Childhood Classroom Observation Measure, Stipek \& Byler, 2005). In this study, I focus on research using the CLASS or Classroom Assessment Scoring System because of a consensus reached at the Garrison meeting in 2009 that the CLASS appeared to capture key aspects of mindfulness in teacher behavior, specifically calmness, clarity, and kindness (see Schoeberlein \& Koffler, 2005). Numerous studies have assessed and used the CLASS observation system as a means of measuring teacher and student interactions in the classroom in order to understand the classroom climate and student engagement. The CLASS is a "theoretically driven and empirically supported framework for looking at classroom interactions" (Pianta \& Hamre, 2009, p.112). While there are different versions of the CLASS, the CLASS-S is an adaptation that focuses specifically on secondary schools and incorporates the needs of adolescents using developmental theory and research (Hafen et al., 2015; see Table B in Appendix A for a summary of studies examining the CLASS-S and student outcomes).

The CLASS-S consists of three domains: emotional support, classroom organization, and instructional support. Each of these domains consists of several dimensions. Emotional support includes positive climate, teacher sensitivity, and regard for adolescent perspectives. Classroom organization consists of behavior management, productivity, and negative climate. Finally, instructional support includes the dimensions 
of instructional learning formats, content understanding, analysis and inquiry, quality of feedback, and instructional dialogue. Each of these dimensions has behavioral indicators that help with coding them. The CLASS-S also includes a measure of student engagement, not classified within the three overarching domains.

While most previous research using the CLASS-S has rated classrooms at the dimension level, the current study rated classrooms, teachers, and students using the behavioral indicators under each dimension. By using the behavioral indicators, it is possible to focus on specific teacher behaviors (given that at the dimension level the CLASS-S assesses the interactions between teachers and students) and target those behaviors that involve calmness, clarity, and kindness - teacher mindfulness in the classroom. Thus, the current study draws upon those behavioral indicators from the CLASS-S that tap into teachers' situated dispositional manners of being calm, clear, and kind. This reinterpretation of the CLASS-S behavioral indicators is not meant to suggest that the CLASS-S is invalid or should be restructured. Rather, it is inspired by and drawing upon these behavioral indicators as a means of measuring key aspects of behavioral manifestations of teacher mindfulness that are naturally occurring in the structure of the CLASS-S.

After using the CLASS observation system for many years, the authors of this measure developed a student self-report of the same dimensions (emotional support, classroom organization, instructional support) in order to capture students' perceptions and compare them to third-person ratings. This measure, called Learning About TeacherStudent Interactions (LATSI), allows elementary students to "rate the quality of their classroom interactions with teachers" (Downer, 2015). This work highlights a path I take 
in this study - using the CLASS-S observation measure to anchor teacher behaviors hypothesized to reflect calm, clear, and kind behaviors in the classroom. These behaviors and the conceptualization of teacher mindfulness as being calm, clear, and kind were also used to create new survey measures given to teachers and students (discussed further in Measures) to measure these same dimensions of teacher mindfulness in the classroom through a multi-concept multi-informant assessment.

\section{Summary of Current Study}

Given the widespread use of self-report measures of teacher dispositional mindfulness in previous studies of teachers in education, with few studies assessing mindful behaviors in the classroom, the current study seeks to create a new reliable and valid measure of teacher mindfulness in the classroom from teacher self-reports, student perceptions, and third-person observations. The validity of this new measure will be tested through its hypothesized positive associations with teacher dispositional mindfulness (self-report) and negative relations with teacher job stress (self-report). 
Chapter Four

\section{Method}

\section{Participants}

Sixty-nine sixth through eighth grade teachers were recruited to participate in the current proposed study as a part of the larger MPower study ran by Drs. Roeser (PI), Mashburn, and Skinner. Teachers came from 24 schools that were either K-8 or 6-8 in structure. Seventy-three percent were female and $71 \%$ were Caucasian. Teachers were on average 40 years old $(S D=8.66)$ and had 9.71 years experience teaching $(S D=7.80)$.

\section{Procedure}

Teachers were recruited through online message boards, word of mouth, and fliers in teacher mailboxes advertising an intervention program to reduce teacher stress. They understood that they would eventually be participating in a randomized-control study in which half of the teachers would be randomly assigned to a wait-list control group and half to a mindfulness intervention. During baseline data collection, teachers completed online surveys, were interviewed by trained research assistants (RAs), and had their classes observed twice by trained RAs. The observations were conducted using the CLASS-S (Pianta \& Hamre, 2009), which all RAs were trained in. Using the CLASS-S, RAs observed for 15 minutes, scored the classroom for 10 minutes, observed again for 15 minutes, and scored for another 10 minutes. For the purposes of the current study, only data from the baseline online surveys and observations were analyzed.

Students were recruited through classroom announcements by teachers and RAs to complete surveys about their teachers and classrooms. Students' names were entered into a raffle for an iTouch for turning in consent forms (whether yes or no) and also for 
filling out surveys. Four hundred ninety-seven students participated in this study from a subsample of 47 of the teachers, averaging 11 students per teacher. Fifty-one percent were female, $55 \%$ were Caucasian, and students were on average 12.34 years old $(\mathrm{SD}=$ 1.00). Students filled out surveys either online or by paper in the classroom taught by the teacher in the study. Surveys were administered by either the teacher or RAs. All paper surveys were placed in sealed envelopes upon completion in order to allow confidentiality of student responses from their teachers.

\section{Measures}

Exact items for each measure are displayed in Appendix B. The measures consist of two different types: teacher mindfulness (disposition, classroom behavior) and teacher job stress.

Teacher mindfulness. Teachers' dispositional mindfulness was collected through self-report using the FFMQ (Baer et al., 2006). In addition, a teacher-self report, a student consensual report, and an observational measure of teachers' mindful behaviors in the classroom were newly created for this proposed study.

Teacher dispositional mindfulness. The FFMQ consists of 24-items that assess five dimensions of dispositional mindfulness: non-reactivity (e.g., "Usually when I have distressing thoughts or images, I just notice them and let go"), describing (e.g., "I'm good at finding words to describe my feelings"), acting with awareness (e.g., "I find it difficult to stay focused on what's happening in the present;" reverse coded), non-judgment (e.g., "I tell myself I shouldn't be feeling the way I'm feeling;" reverse coded), and observing (e.g., "I pay attention to sensations, such as the wind in my hair or sun on my face"). Previous studies have demonstrated good internal reliability for this measure $(\alpha=.72-.92$ 
for each facet; Baer et al., 2006). Responses were rated on a 5 -point scale $(1=$ never or very rarely true, $5=$ very often or always true) and averaged from each dimension to create a total score of dispositional mindfulness $(a=.88, M=3.22, S D=.43)$. Teachers' scores on the FFMQ have been shown to mediate the effects of mindfulness training on teachers' job stress, burnout, and overall well-being at work and home (Crain, SchonertReichl \& Roeser, in press; Roeser et al., 2013).

Teacher mindfulness in the classroom. A suite of three measures of teacher mindfulness in the classroom were created for this study drawing upon teacher selfreports, student perceptions, and third-person observations.

Generation of the teacher and student survey item pools. Based on the conceptualization of teacher mindfulness as calmness, clarity, and kindness, as well as the antitheses of reactivity, distractedness, and criticalness (see Table 1), mindfulness and developmental science experts conducted an iterative process in which items were identified or created, adapted, and selected. For the teacher survey, existing scales of mindfulness and mindful teaching were reviewed. From these scales, some items were adapted. However, most items were newly created, resulting in a set of 10 to 15 items that corresponded to each of the three dimensions of mindfulness and their antitheses. Items were grouped according to constructs and discussed further in terms of their face validity and conceptual correspondence. Over several sessions, the wording of items was changed and new items were created to reflect the lived experiences of teachers in their own language. Throughout this cyclical process, items were removed, introduced, created, and selected based on how well they reflected the conceptualizations of calmness, reactivity, clarity, distractedness, kindness, and criticalness and how well they 
were appropriately worded for the target population. For data collection, a total of 31 items were selected for the teacher surveys. These items were a combination of newly created items and ones adapted from and inspired by other measures (e.g., FFMQ, Baer et al., 2006; Mindfulness in Teaching Scale, Frank et al., 2016; Occupational SelfCompassion, Neff, 2003; Roeser et al., 2013).

For the student survey, existing measures of students' perceptions and experiences of teacher mindfulness could not be found. In light of this, measures of students' perceptions of the classroom climate and teacher behaviors were used (e.g., LATSI, Downer, 2015; Classroom Environment Scale, Moos \& Trickett, 1987). As a result, the creation of this item pool relied largely on multiple discussions aimed at conceptualizing how students might experience teachers who are calm, clear, and kind, as well as reactive, distracted, and critical. Attempts were made to ensure that the conceptualizations of the student experience of teacher mindfulness corresponded with the definitions of mindfulness presented in Table 1 . However, no attempts were made to construct items parallel to those in the teacher survey since it was assumed that students' and teachers' experiences would be complementary rather than matching (e.g., Wang \& Eccles, 2014). For example, for the teacher-report item "When things go wrong, I bounce back pretty fast," the corresponding but not matching student-report item was "No matter what happens in class, our teacher can handle it." A total of 23 items were selected for inclusion in the student surveys.

Choosing observational indicators of teacher mindfulness. For the observer reports of teacher mindfulness in the classroom, the CLASS-S's behavioral indicators were examined. Indicators that predominantly focused on teacher behaviors were selected 
and then sorted by mindfulness and developmental science experts into the categories of calm, reactive, clear, distracted, kind, and critical to ensure face validity of these indicators. A total of 16 behavioral indicators were chosen from this process. Due to the scarcity of indicators reflecting the antithesis items, these indicators were combined with their positively-valenced counterparts (e.g., reactive reverse-coded and combined with calm).

Teacher reports of teacher classroom mindfulness. This measure was used to assess teachers' perceptions of their mindful behaviors while teaching in the classroom. Thirty-one items centered on the key aspects of mindfulness of calmness (5 items), clarity (5 items), and kindness (5 items), as well as the antitheses of reactivity (5 items), distractedness (5 items), and criticalness (6 items). All antitheses items were reversecoded so as to be positively-valenced, however, from here on they are still referred to as reactive, distracted, and critical despite being reverse-coded. Sample calm items included "When I am upset with my class, I can still calmly communicate how I am feeling" and "If I get upset in class, I get over it quickly" $(\alpha=.79)$. Reactive items included "When my class upsets me, it takes me a long time to calm down" and "When students do something wrong, I tend to over-react" amongst others (reverse-coded; $a=.75$ ). Some items for clear included "When I am in the classroom, I am fully focused on teaching" and "When class is not going well, I can find the right words to explain to students what is happening" ( $\alpha=.61)$ while some distracted items included "When I am teaching I seem to be running on automatic without much awareness of what I am doing" and "I can get so busy thinking about other things that I am not really listening to my students" (reverse-coded; $a=.73$ ). Sample kind items consisted of "When my students are going 
through a hard time, I try to give them the caring and nurturing they need" and "I feel tender towards my students and all they are dealing with" $(\alpha=.60)$. Some critical items included "If students do not do well in my class, they only have themselves to blame" and "When dealing with problem students, I often find myself thinking, 'What is wrong with you?'" (reverse-coded; $a=.68)$. Responses were rated on a 5-point scale $(1=$ almost never, 5 = almost always).

Student reports of teacher classroom mindfulness. Students were asked to think about their teachers and rate 23 statements targeting how calm (3 items), reactive (4 items), clear (3 items), distracted (3 items), kind ( 7 items), and critical (3 items) their teachers typically are on a 5 -point scale $(1=$ not at all true, $5=$ totally true $)$. All antitheses items (reactivity, distractedness, and criticalness) were reverse-coded. Sample items included "Even when we mess up, our teacher deals with us in a calm and fair way" $(\mathbf{c a l m} ; \alpha=.90)$, "My teacher gets irritated pretty easily" (reverse-coded reactive; $\alpha=.84)$, "My teacher knows when I need extra help" (clear; $a=.77)$, "My teacher often gets off track and we end up missing part of the lesson" (reverse-coded distracted; $\alpha=72$ ), "My teacher takes a personal interest in students" (kind; $a=.90)$, and "My teacher "talks down' to students" (reverse-coded critical; $\alpha=73$ ). Student responses were aggregated for each classroom to the level of the teacher for purposes of analysis in this study. As such, these consensual reports represent "second-person" measures of teacher mindfulness in the classroom - those by "experts" who participate in the context every day and have their own informed perceptions on the behavior of another.

Observer reports of teacher classroom mindfulness. A third-person, observational measure of teacher mindfulness in the classroom was also created based on ratings of 16 
indicators from the CLASS-S. To derive this measure, live classroom raters coded not just the overall dimensions of the CLASS-S, but also the behavioral indicators that underpin these dimensions. Each indicator was rated on a 5-point scale by observers $(1=$ low, 5 = high). Indicators chosen as representing calm teacher behaviors in the classroom included effective redirection of misbehavior, proactive, and punitive control (reversecoded; $a=.86)$. Indicators selected for clear teacher behaviors in the classroom were maximizing learning time, routines, effectiveness in addressing problems, awareness, clear expectations, preparation, and building on student responses $(a=.91)$. Indicators chosen for kind teacher behaviors included encouragement and affirmation, respect, positive communications, responsive to needs, positive affect, and disrespect (reversecoded; $a=.86$ ). Table 2 summarizes each behavioral indicator under calm, clear, and kind.

Teacher job stress. Teachers rated how stressed they are at work with seven statements rated on a 5-point scale $(1=$ strongly disagree, $5=$ strongly agree; Lambert, McCarthy, \& Abbott-Shim, 2001), such as "I find dealing with student motivational and disciplinary problems to be very stressful," "There is a lot of stress at work just keeping up with changing professional standards," and "Stress at work makes me irritable at home" $(\alpha=.65, M=3.44, S D=.58)$. 


\section{Results}

\section{Preliminary Analyses}

Item selection and reduction. After data collection, the items from the teacher, student, and observer reports of teacher mindfulness were reduced for the purposes of analysis in this thesis. This was accomplished through statistics (reliability analyses, EFAs, and CFAs) and considerations of face validity and parsimony. For each informant source, EFAs were first conducted on the items. For teacher and student survey measures, these analyses were used to assess if the total pool of items assessed six dimensions (calm, reactive, clear, distracted, kind, critical) or three dimensions (calm-reactive, cleardistracted, kind-critical). For the observational measure, only three dimensions (calm, clear, kind) were examined since there were not enough antitheses items. Each of these EFAs was conducted separately for each possible dimension for each informant (e.g., calm and reactive items were analyzed separately from clear and distracted items). Second, reliability analyses were conducted on these emergent dimensions. Third, CFAs were conducted to confirm these emergent dimensions. Finally, CFAs were conducted to examine each of these confirmed dimensions simultaneously in a model (e.g., calm and reactive items with clear, distracted, kind, and critical items in a single model), for each informant source separately, to confirm overall six, three, or one dimensions. Composite variables of these finalized dimensions were created for each informant source. Below I briefly describe the results of these preliminary analyses for each informant source.

Reduction of teacher survey items. To see if the pool of items designed to measure teacher reports of calm vs. reactive, clear vs. distracted, and kind vs. critical 
behaviors in the classroom separated into two-factor structures (e.g., calm vs. reactive) or one-factor structures (e.g., calm-reactive), a series of EFAs and reliability analyses were conducted. Items that had factor loadings .4 and above and good internal consistency with other items in each scale were retained for further analysis, totaling 28 items (see Appendix B for these items, denoted with an asterisk). Based on the results of these firstorder analyses, CFAs were conducted on the retained items. Results for teacher reports of calm and reactive, clear and distracted, and kind and critical item sets showed that either two-factor or one-factor solutions were acceptable for each construct set (e.g., calm and reactive) based on factor loadings and reliabilities.

Reduction of student survey items. Similar to the teacher survey items, a series of EFAs and reliability analyses were conducted to determine if the student survey pool of items separated into two-factor structures (e.g., calm vs. reactive) or one-factor structures (e.g., calm-reactive). Again, items that had factor loadings .4 and above and good internal consistency with other items in each scale were retained for scale creation. This resulted in 18 items (see Appendix B for these specific items). Results for the student reports of calm and reactive, clear and distracted, and kind and critical items showed that a onefactor solution (e.g., calm-reactive) was best for these item sets based on factor loadings, internal reliabilities, and high correlations between factors.

Reduction of the classroom observational indicators. For the observer reports, one-factor structure models of calm-reactive, clear-distracted, and kind-critical were only examined since only two of the behavioral indicators corresponded with the antitheses (reactive: Punitive Control; critical: Disrespect). Results for the observer ratings showed one-factor solutions for each item set (calm, clear, kind) had acceptable factor loadings 
and internal reliabilities for each dimension, resulting in the retention of all 16 original indicators.

Descriptive statistics for all selected items from the teacher, student, and observer reports are presented in Table 3.

\section{Confirmatory analyses for retained items in single models. Further}

confirmatory analyses for these narrowed down items were ran using structural equation modeling (SEM), which is used to "express a theoretical model in terms of linear and nonlinear expressions with observed and unobserved variables" (McArdle, 2009, p.580). As a result of these model expressions, predicted expectations for means and variances are produced and compared to observed data using various goodness-of-fit tests (McArdle, 2009). This framework is especially useful for testing confirmatory factor analysis (CFA) models that include predictor and outcome variables. Also, Castro-Schilo, Widaman, and Grimm (2013) have found SEM to be an appropriate framework for analyzing data that has an inherent multi-trait multi-informant nature.

SEM was used to create measures of calm, clear, and kind teacher mindful behaviors in the classroom from the retained items from each informant source (teachers, students, observers) that emerged from the preliminary analyses. As described below, a series of CFA models were conducted in which the latent variables calm, clear, and kind were expected to be identified by specific variables from each source of measurement. Given the relatively small sample size in this study which may bias model fit estimates, the focus was on factor loading magnitudes and significance in order to assess adequate model fit. Specifically, adequate fit was determined if the factor loadings were significant and at least .4. Overall model fit indices are still reported in the model figures. 
Teacher measure. Figure 2 depicts the proposed CFA model for the teacher self-

reports. Based on the preliminary analyses, items that pertain to teachers behaving calmly in the classroom were hypothesized to identify the latent variable calm, items for reactive would identify the latent variable reactive, those describing teachers behaving clearly would identify the latent variable clear, those denoting teachers behaving distractedly would identify the latent variable distracted, items about teachers behaving kindly would identify the latent variable kind, and finally items about teachers behaving critically would identify the latent variable critical. Each of the calm, clear, and kind latent variables were expected to be moderately and positively related to one another given that they are each a key aspect of mindfulness, just as the reactive, distracted, and critical latent variables were expected to be moderately and positively related to one another. Finally, each corresponding set of latent variables were hypothesized to be positively (since the antitheses were reverse-coded) and significantly related to one another (e.g., calm and reactive). It was expected that this proposed CFA model would have adequate fit for the data.

Figure 3 depicts the actual factor loadings for this model. While there was overall poor model fit as well as numerous standardized residuals above $|2.00|$ (see Table 4), all factor loadings were significant and all but seven were .4 and above in magnitude (rReact1, rReact5, Clear1, Clear3, rDistract1, rDistract2, and Kind5). Due to face validity and previous reliability analyses, each of these indicators was retained. These results suggest that this six-factor model could be used with the teacher items. However, to provide parallels with the student and observer measures, a three-factor model was also conducted in which each of the reverse-coded antitheses items were hypothesized to 
identify its corresponding positively-valenced latent variable (e.g., reverse-coded reactive items would identify the calm latent variable along with the calm items). Figure 4 depicts the factor loadings for the three-factor model. As predicted given the small sample size, there was evidence of poor model fit. This could also be due to numerous standardized residuals greater than $|2.00|$, as shown in Table 5. Nonetheless, there were significant factor loadings for all the items. However, two of these had magnitudes below .4 for clear (Clear3 and rDistract1) and three for kind (Kind1, Kind5, and rCritical4). Given that these items had good face validity, were reliable with the other items, and still had significant loadings, these five items were retained in the model. Of note, the latent variables in this model were positively and strongly related to one another (e.g., calmclear: $r=.86$, calm-kind: $r=.76$, clear-kind: $r=.68$ ). A chi-square difference test showed that there was a significant difference between the six-factor and three-factor models, such that the six-factor model was a better fit with regard to AIC and BIC values (see Table 6). However, for parsimony reasons and to allow for a comparison with the student and observer models, the six-factor model was not retained. Of note, a six-factor model could be used for the teacher items in future studies.

Because the correlations among the three dimensions in the three-factor model were larger than expected, suggesting multicollinearity between the three constructs, a one-factor CFA was also conducted. This one-factor "teacher mindful behavior" alternative model, presented in Figure 5, also had poor overall model fit as well as numerous standardized residuals above $|2.00|$ (see Table 7). At the same time, all but one of the factor loadings were significant and nine were below .4 in magnitude (rReact2, rReact5, Clear1, Clear3, rDistract1, Kind5, rCritical4, rCritical5, and rCritical6). Given 
the face validity and reliabilities of these items, all items were retained in this one-factor model. A chi-square difference test was conducted to compare these two models. As shown in Table 8, there was a significant difference between the models. The AIC and BIC for the three-factor model was lower than that of the one-factor model. In sum, the three-factor model with calm, clear, and kind latent variables for the teacher items was retained since it had a better fit, comparatively, and also because it provided a factor solution conceptually identical to those for students and observers, described below.

Student measure. Figure 6 portrays the proposed CFA model for student perceptions of calm, clear, and kind teacher behaviors in the classroom. Based on the preliminary analyses, items pertaining to calm teacher behaviors were expected to identify the latent variable calm, clear teacher behaviors would identify the latent variable clear, and kind teacher behaviors were anticipated to identify the latent variable kind. As with the previous proposed CFA models, the latent variables calm, clear, and kind were expected to moderately relate to one another given their foundation in mindfulness. This CFA model was also expected to have adequate fit for the data.

As shown in Figure 7, there was not good overall model fit and as shown in Table 9, several standardized residuals were above $|2.00|$. However, all but one of the factor loadings were significant and three were below .4 in magnitude (Kind4, Kind5, rCritical1). Due to their face validity and previous reliability, each of these items was retained. There were very large and significant correlations between the three latent factors (calm-clear: $r=.88$, calm-kind: $r=1.00$, clear-kind: $r=.94$ ), suggesting multicollinearity. As such, an alternative one-factor CFA model was conducted. Figure 8 depicts the results of this alternative CFA model. This model also had poor overall fit, 
which could in part be due to several standardized residuals greater than $|2.00|$ (see Table 10). All but one of the factor loadings were significant and only one was below .4 (Kind5). Given the reliability and face validity of this item, it was retained in this model. A chi-square difference test was conducted between the three- and one-factor models and is depicted in Table 11. The three-factor model with calm, clear, and kind latent variables was retained since there was a significant difference between the two models and it had lower values for the AIC and BIC, suggesting better overall fit.

Observational measure. A CFA model was tested using SEM in which the chosen mindful CLASS indicators from the third-person observations were expected to identify their corresponding latent variables of calm, clear, and kind. Figure 9 depicts the proposed CFA model in which the latent variable calm was predicted to be identified by the chosen calm indicators. Clear was hypothesized as being identified by the selected clear indicators. Kind was thought to be identified by the chosen kind indicators. Each of these latent variables were proposed to be moderately related, and it was expected that this proposed CFA model would have adequate fit for the data.

Figure 10 shows the actual factor loadings after running this model. As expected from the small sample size, this model had poor fit for the data. In addition, several of the standardized residuals were above $|2.00|$ (see Table 12). Despite this, all factor loadings were significant and .4 and above in magnitude. However, there were strong correlations between each latent factor (calm-clear: $r=.95$, calm-kind: $r=.66$, clear-kind: $r=.82$ ). Since these high correlations suggested multicollinearity, a one-factor CFA was conducted, as depicted in Figure 11. This alternative one-factor model also had poor fit and several standardized residuals above $|2.00|$ as shown in Table 13. All factor loadings 
were significant though and only one was below .4 in magnitude (Encouragement and Affirmation). Given the reliability and face validity of this item, it was retained. Next, a chi-square difference test was run between these two models (see Table 14), which was significant. The three-factor model was retained due to its lower AIC and BIC values which suggest a better fit than the one-factor model.

Creating composite scales across informants. In sum, a three-factor latent structure was found for the teacher, student, and observer indicators. Since the threefactor CFAs had better fit compared to the one-factor CFA models, for calm, clear, and kind combined, three composite variables were created for each informant source: teacher reports of calm, clear, and kind; student reports of calm, clear, and kind; and observer reports of calm, clear, and kind. Table 15 reports the means, standard deviations, minimums, maximums, and reliabilities of these nine composite variables. Of note, all nine composites demonstrated good internal reliability (Cronbach's alphas $>.70)$.

\section{Testing the Reliability and Validity of Teacher Mindfulness in the Classroom}

To test the first hypothesis of this thesis, given the construction of the latent variables, a multi-trait multi-informant (MTMI) CFA model (see Figure 12) was originally proposed using SEM in order to examine the reliability and validity between calm, clear, and kind and each informant (teacher self-report, third-person observations, and student perceptions). Based on Campbell and Fiske's (1959) guidelines and CastroSchilo et al.'s (2013) correlated trait-correlated method model, it was expected that (1) evidence for convergent validity would be demonstrated by strong, significant factor loadings from each latent trait factor to their corresponding indicators; (2) evidence of method effects would be supported through strong, significant factor loadings from each 
latent method factor to their corresponding indicators; and (3) support for discriminant validity would be evident through low to moderate correlations between each trait latent variable. Overall, it was anticipated that this CFA model would have adequate fit for the data with significant factor loadings of at least .4. However, this model would not converge. Thus, model fit estimates could not be calculated and factor loading estimates could not be relied upon.

Instead, two separate CFA models were conducted, one examining calm, clear, and kind from the nine composites and the other examining method latent variables from the nine composites. Figure 13 depicts the results of the first model examining the latent variables of calm, clear, and kind, which shows that convergent validity was only demonstrated for the latent variable clear in which teacher, student, and observer reports each had positive and significant factor loadings. Calm and kind did not demonstrate convergent validity between teacher, student, and observer reports. Evidence of discriminant validity was supported by low to moderate significant correlations between calm, clear, and kind. However, this model did have negative variances as well as some standardized residuals greater than $|2.00|$, as shown in Table 16. That and the small sample size call into question the dependability of these CFA results.

Figure 14 shows the results of the second model analyzing the method latent variables. Here, each informant source composite had positive and significant factor loadings to its corresponding method latent variable (e.g., teacher reports of calm, clear, and kind each significantly identified the teacher-report latent variable). Again, this model had negative variances and some standardized residuals greater than $|2.00|$ (see Table 17), calling into question the reliability of this model's estimates. Nonetheless, this 
model suggests that there are significant method effects for each informant source of teachers' calmness, clarity, and kindness in the classroom.

\section{Teacher Mindfulness in the Classroom, Dispositional Mindfulness, and Job Stress}

Given the small sample size, negative variances, an inability for a total MTMI CFA model to converge, and the lack of convergent validity for the calm and kind latent variables, the second hypothesis of analyzing the concurrent validity of teacher mindfulness in the classroom was not examined using SEM. Instead, alternative OLS regression analyses were conducted to re-examine the reliability and validity of teacher mindfulness in the classroom through Campbell and Fiske's (1959) traditional MTMI matrix as well as correlational and regression analyses with the proposed antecedents of teacher dispositional mindfulness and job stress.

\section{OLS MTMI Analyses}

Given the good internal consistencies for the nine composite variables as previously demonstrated (see Table 15), an MTMI matrix was created from these nine composites allowing for examination of convergent validity between these measures. According to Campbell and Fiske (1959), convergent validity is supported if the correlations between the same traits (e.g., calm) across different informants (e.g., teachers, students, observers) are each above zero. As shown in Table 18, teacher and observer reports significantly converged only for measures of clarity; teacher and student reports did not significantly converge for any of the key aspects of mindfulness; and observer and student reports significantly converged for calmness, clarity, and kindness. Table 18 also shows the within-informant correlations for calmness, clarity, and kindness. Each informant had moderate to strong correlations between calm, clear, and kind. Given 
these overall strong within-informant correlations and moderate evidence of convergent validity, these nine composites were not collapsed into three overall composites of calmness, clarity, and kindness. Rather, they were kept as nine separate composites in order to allow for some control in examining potential method effects, given the significant findings from the CFA model conducted above (see Figure 14).

\section{OLS Concurrent Validity Analyses}

Correlations. The second research question was addressed by first conducting correlation analyses between the nine composites of the teacher mindfulness in the classroom measure with the proposed antecedents (teacher dispositional mindfulness and job stress). These results are depicted in Table 19. Teacher reports of dispositional mindfulness (as measured by a total score on the FFMQ) were positively and significantly related to teacher reports of calmness, clarity, and kindness in the classroom environment, but were not significantly correlated with any of the observer or student reports. Teacher reports of job stress were significantly and negatively related to teacher reports of calmness and clarity, but not kindness. Teacher job stress was also positively and significantly related to student reports of teacher calmness. No other correlations were significant for the observer or student reports.

Regression analyses. Regression analyses were also conducted to examine the predictive (not causal) relations between teacher dispositional mindfulness and job stress (simultaneous predictors) and calmness, clarity, and kindness from each informant source (separate outcomes) from the teacher mindfulness in the classroom measures. The regression equations for these analyses are presented below:

$$
y_{\text {Tcalm }}=\beta_{0}+\beta_{F F M Q}+\beta_{\text {Tstress }}+e
$$




$$
\begin{aligned}
& y_{\text {Tclear }}=\beta_{0}+\beta_{F F M Q}+\beta_{\text {Tstress }}+e \\
& y_{\text {Tkind }}=\beta_{0}+\beta_{F F M Q}+\beta_{\text {Tstress }}+e \\
& y_{\text {Ocalm }}=\beta_{0}+\beta_{F F M Q}+\beta_{\text {Tstress }}+e \\
& y_{\text {Oclear }}=\beta_{0}+\beta_{F F M Q}+\beta_{\text {Tstress }}+e \\
& y_{\text {Okind }}=\beta_{0}+\beta_{F F M Q}+\beta_{\text {Tstress }}+e \\
& y_{\text {Scalm }}=\beta_{0}+\beta_{F F M Q}+\beta_{\text {Tstress }}+e \\
& y_{\text {Sclear }}=\beta_{0}+\beta_{F F M Q}+\beta_{\text {Tstress }}+e \\
& y_{\text {Skind }}=\beta_{0}+\beta_{F F M Q}+\beta_{\text {Tstress }}+e
\end{aligned}
$$

As depicted in Table 20, teacher dispositional mindfulness significantly and positively predicted teacher reports of their calmness, clarity, and kindness in the classroom. Teacher job stress did not significantly predict any of these aspects of mindfulness over and above teacher dispositional mindfulness. These three models explained between $10 \%$ and $21 \%$ of the variance in each of these outcomes. Teacher dispositional mindfulness and job stress did not significantly predict teacher calmness, clarity, or kindness as reported by observers (see Table 21) or students (see Table 22). 
Chapter Six

\section{Discussion}

\section{Summary and Explanation of Findings}

The purpose of this study was to create a new reliable and valid measure of teacher mindfulness in the classroom, focusing on the embodied characteristics of calmness, clarity, and kindness as reported by teachers, students, and observers. The first research question focused on the creation of this new measure from the three informant sources. Through a series of confirmatory factor analyses examining each informant source separately, it was found that while overall each latent variable of calmness, clarity, and kindness was significantly identified by its corresponding indicators, these latent variables were highly correlated with one another (see Figures 4, 7, and 10). Such high correlations demonstrated multicollinearity between the constructs. However, these threefactor models had better fit than one-factor models (see Tables 8, 11, and 14). This suggests that while calm, clear, and kind are not distinct constructs (separate and low to zero correlations), they are distinguishable (separate with high correlations). The theoretical framework of this thesis argues that teachers' abilities to be emotionally regulated and stable, focused and fully present, and empathic and compassionate in the classroom all stem from a common source: teachers' situated dispositional mindfulness. As such, while specific behaviors might predominately demonstrate one construct over another, they still stem from mindfulness and might reflect different degrees of each aspect (e.g., high calmness, medium clarity, low kindness). This would account for the high correlations between these three constructs as distinguishable but not distinct aspects of teacher mindfulness in the classroom. 
Although a correlated trait-correlated method model (Castro-Schilo et al., 2013)

could not be examined due to negative variances, a small sample size, and a lack of model convergence, two separate CFA models were analyzed looking at the key aspects of calm, clear, and kind as well as method effects. Evidence of convergent validity was only found for the latent variable clear (see Figure 13). However, there were strong implications of method effects in the second model for each informant source (see Figure 14). Campbell and Fiske's (1959) traditional MTMI matrix (using OLS) further confirmed mixed effects for convergent validity for these nine composite variables (see Table 18). While students and observers were significantly correlated with one another for each aspect of mindfulness, teachers and students were not and teachers and observers were only significantly related for clarity.

These findings suggest that while students and observers have some overlap in their perceptions of mindful teacher behaviors in the classroom context, teachers' selfreports of their own mindful behaviors are not aligning with either (with the exception of clarity with observer reports) in this sample. This could stem from the fact that internally, these teachers do not feel as if they are being mindful within and without, despite the fact that perhaps they are exuding calmness, clarity, and kindness in their outward behaviors in front of students and observers. These findings also fall in line with that of Wang and Eccles' (2014) finding that teachers and students view the classroom context differently: teacher and student perceptions had low correlations and only half were significant in their study. The lack of overlap between teacher and student reports of teacher mindfulness might also be due to the creation of these two survey measures. While survey items focused on calm, reactive, clear, distracted, kind, and critical, items from 
each survey did not directly mirror one another. With the goal of making items understandable and applicable to each participant (i.e., teachers versus students), teacher and student items corresponded with one another for calm, reactive, clear, distracted, kind, and critical but were not exact duplicates. As mentioned in the Methods, the teacher-report item "When things go wrong, I bounce back pretty fast," corresponded to the student-report item "No matter what happens in class, our teacher can handle it." Thus, some of the discrepancy between teacher and student reports of teacher mindfulness in the classroom could be a result of these slightly differing survey items. However, the lack of convergence between the teacher and student reports may also be due to the small sample size in this study.

The second research question focused on the concurrent validity of the separate composites of teacher, student, and observer reports with teacher dispositional mindfulness and job stress. These relations could not be examined using SEM due to the negative variances, low sample size, and lack of converging models. However, OLS correlation and regression analyses found that teacher dispositional mindfulness (FFMQ) was positively related to and predicted teacher reports of calmness, clarity, and kindness (see Tables 19 and 20). Teacher job stress was negatively related to teacher reports of calmness and clarity. Teacher job stress was also positively related to student reports of teachers being calm in the classroom. This could be further evidence of the disconnect between teacher and student reports of teacher mindfulness, such that even when teachers feel and report being stressed, their students still perceive them as being calm. Thus, teachers might be exuding calm behaviors in the classroom despite feeling internal job stress. All other correlations and regressions were non-significant between the 
antecedents and nine composites signifying only partial support for the second hypothesis (see Tables 20, 21, and 22). Yet, due to the strong evidence of method effects in the method latent variables CFA model (see Figure 14), the significant correlations between teacher dispositional mindfulness, job stress, and mindfulness in the classroom could be due to common method bias since each of these was a teacher self-report measure.

In addition, while teacher job stress was negatively and significantly correlated with teacher reports of calmness and clarity, it did not significantly predict teacher reports of calmness, clarity, or kindness when in a regression model with teacher dispositional mindfulness (as measured by the FFMQ). This could be because the teacher job stress measure had a lower than anticipated reliability (.65), impacting the ability of this measure to predict outcomes.

\section{Limitations and Future Directions}

The current study has certain limitations. The small sample size of this study posed a problem in the SEM analyses in determining good model fit. Overall model fit indices could not be relied upon for assessing model fit since they are sample size dependent. As such, factor loadings' magnitudes and significances had to be used instead. In addition, the small sample size as well as negative variances made it impossible for some of the CFA models to converge. In the future, these measures of teacher mindfulness in the classroom should be examined with larger samples of teachers to allow for the convergence of these CFA models, an examination of overall model fit indices, and greater insight into the underlying structures of these measures.

In addition, future studies could examine these measures through hierarchical CFA models for a more nuanced and versatile assessment and conceptualization of 
teacher mindfulness in the classroom. For example, teacher calmness, clarity, and kindness could conceptually identify a latent variable of teacher mindfulness while reactivity, distractedness, and criticalness could identify a latent variable of teacher mindlessness. Thus, this suite of measures could be examined either as six distinct factors; three factors of calm, clear, and kind; two factors of mindfulness and mindlessness; or one factor of overall teacher mindfulness in the classroom, as measured by teachers, students, and observers.

Another limitation is that the lack of longitudinal data weakened the proposition that teacher dispositional mindfulness predicts teacher reports of mindful teacher behaviors in the classroom - causal relations could not be determined from this data. Since only baseline data collection was used in this study's analyses, a longitudinal design could have only been used with the control group, which would have decreased the sample size further. Thus, future studies should examine the validity of this measure with a longitudinal sample to examine these predictive relations in a causal framework.

Further, the proposed antecedent measures used in this study to determine the concurrent validity of the teacher mindfulness in the classroom measures were each selfreport measures: teacher dispositional mindfulness and job stress. Given the possibility of method effects in the findings that these measures were only correlated with the teacher reports of calmness, clarity, and kindness, an important next step would be to include more objective measures of concurrent validity. For example, salivary cortisol could be used to more objectively measure teachers' stress levels in connection to their mindful behaviors in the classroom. In addition, previous intervention studies have shown significant decreases in teachers' reports of work burnout after completing a 
mindfulness training (Flook et al, 2013; Roeser et al., 2013), so this could be another useful measure of concurrent validity to examine, despite it being another self-report measure.

In addition, the calm, clear, and kind teacher mindfulness in the classroom measures are newly created and have mixed convergent and concurrent validity results, questioning the efficacy of these measures with other samples of teachers, especially since the sample in this study was predominately Caucasian. While the sample was representative of Portland (a primarily European-American city), it is not representative of other urban areas in the country. Thus, future studies should use more diverse samples when continuing to examine the reliability, convergent validity, and concurrent validity of these measures. A larger sample size might also allow for the convergence of the teacher and student reports, as only 44 teachers had complete data in looking at the correlations between teacher and student reports of teacher mindfulness in the classroom.

There are also potential selection biases in teachers who showed up for this particular study given that teachers volunteered to participate in a mindfulness training study. As well, there are sampling differences for which participants had full teacher, student, and observer data to analyze (i.e., 69 teachers were enrolled in the study but only 47 had student reports and 62 had observer reports). Thus, both the internal and external validity of these findings will need to be examined in future studies.

In light of these limitations, future studies attempting to extend or replicate this thesis should test the validity of the teacher mindfulness in the classroom measures with different, larger samples of teachers so as to further examine the reliability and validity of measurements of teacher mindfulness in the classroom. 


\section{Implications}

Despite evidence of method effects, a lack of strong evidence for convergent validity between the three informant sources, and only partial support for concurrent validity, this thesis has implications for research on mindfulness in the school context. The creation of a suite of new teacher mindfulness in the classroom measures as derived from three informant sources potentially allows for a more robust and reliable measurement of teacher mindfulness in the classroom, which is sorely lacking from the literature currently (Jennings, 2014; Roeser \& Eccles, 2015). Given that most previous intervention studies examining teacher mindfulness have used self-report measures for both predictor and outcome variables and in measuring mindfulness itself (Davidson \& Kaszniak, 2015), the inclusion of other informant reports of teacher mindfulness is important in order to address the potential limitations caused by common method bias and socially desirable responses from participants (Dotterer \& Lowe, 2011). In addition, previous studies have found that teachers and students do not view the classroom environment the same (Wang \& Eccles, 2014). Therefore, it is important to include both of these informant sources in addition to third-person observations in order to gain a fuller understanding of how mindful teacher behaviors manifest in the classroom context.

Thus, with further examination of the internal and external reliability and validity of these suite of measures with larger, more diverse samples, the potential limitations of previous measures of mindfulness might be addressed by focusing on teachers' behaviors of calmness, clarity, and kindness in the classroom context, as reported by teachers, students, and observers. 
Table 1

Definitions of Calm, Clear, Kind, and Antitheses

Mindfulness Antithesis

Calm

Stable, resilient, non-reactive, emotionally regulated

\section{Clear}

Focused, aware, alert, fully present

Kind

Compassionate, empathic, perspectivetaking, forgiving

\section{Reactive}

Ruminative, rushed, emotionally imbalanced

\section{Distracted}

Confused, chaotic

\section{Critical}

Blaming others, self-focused 
Teacher Mindfulness in the Classroom

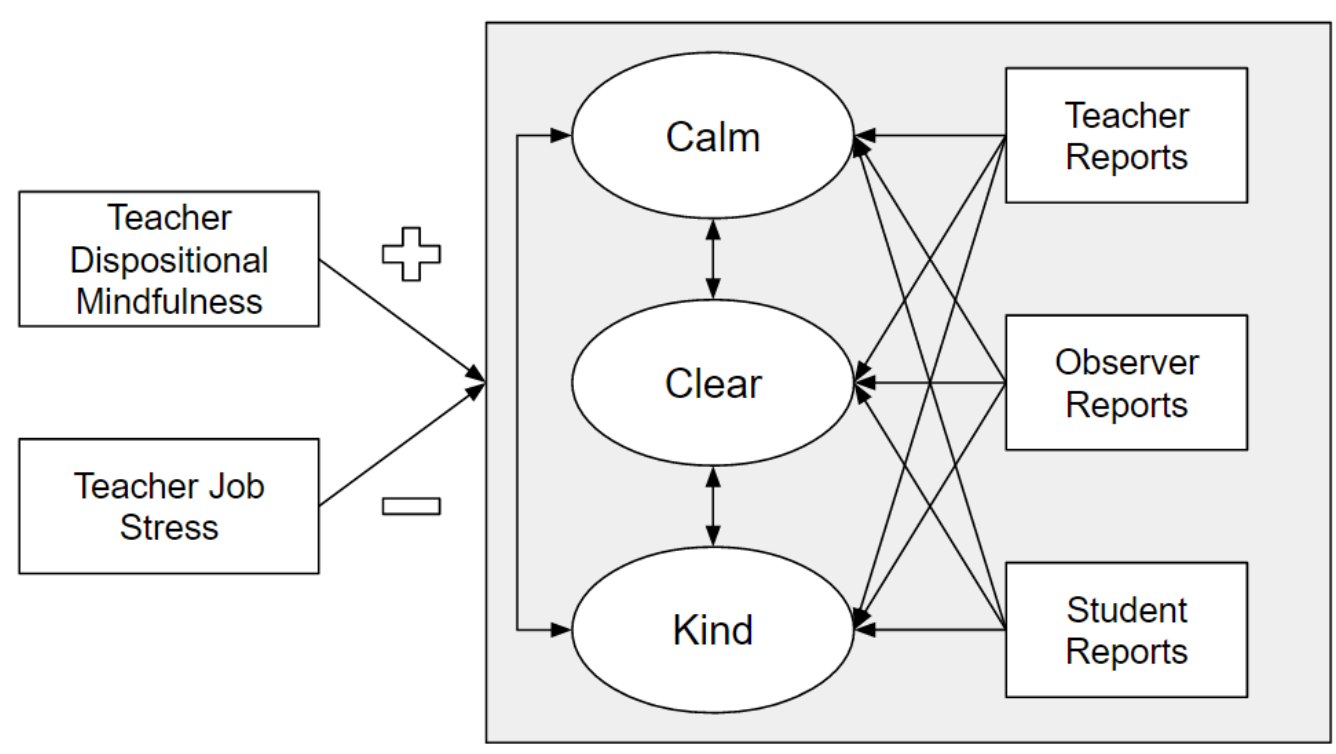

Figure 1. Conceptual model of study. 
Table 2

Behavioral Indicators from the CLASS-S for Teacher Mindfulness in the Classroom

\begin{tabular}{|c|c|c|}
\hline $\begin{array}{l}\text { Teacher Mindfulness in } \\
\text { the Classroom Dimension }\end{array}$ & $\begin{array}{l}\text { CLASS-S Behavioral } \\
\text { Indicator }\end{array}$ & CLASS-S Description \\
\hline \multirow[t]{3}{*}{ Calm } & $\begin{array}{l}\text { Effective redirection of } \\
\text { misbehavior }\end{array}$ & $\begin{array}{l}\text { Uses subtle cues to redirect; } \\
\text { peer redirection and problem } \\
\text { solving; problems resolved; } \\
\text { little time lost }\end{array}$ \\
\hline & Proactive & $\begin{array}{l}\text { Monitoring; anticipation of } \\
\text { problem behavior; } \\
\text { proximity; attention to the } \\
\text { positive; low reactivity }\end{array}$ \\
\hline & Punitive control (r) & $\begin{array}{l}\text { Yelling; threats; harsh } \\
\text { punishment; physical control }\end{array}$ \\
\hline \multirow[t]{7}{*}{ Clear } & Maximizing learning time & $\begin{array}{l}\text { Tasks provided; disruptions } \\
\text { minimized; choice when } \\
\text { finished; effective } \\
\text { completion of managerial } \\
\text { tasks }\end{array}$ \\
\hline & Routines & $\begin{array}{l}\text { Students know what to do; } \\
\text { clear instructions; little } \\
\text { wandering }\end{array}$ \\
\hline & $\begin{array}{l}\text { Effectiveness in addressing } \\
\text { problems }\end{array}$ & $\begin{array}{l}\text { Student issues/questions } \\
\text { resolved; follow up }\end{array}$ \\
\hline & Awareness & $\begin{array}{l}\text { Checks in with students; } \\
\text { anticipates problems; notices } \\
\text { difficulties }\end{array}$ \\
\hline & Clear expectations & $\begin{array}{l}\text { Explicit; consistent; students } \\
\text { know what to do }\end{array}$ \\
\hline & Preparation & $\begin{array}{l}\text { Materials ready and } \\
\text { accessible }\end{array}$ \\
\hline & $\begin{array}{l}\text { Building on student } \\
\text { responses }\end{array}$ & $\begin{array}{l}\text { Expansion; clarification; } \\
\text { specific feedback }\end{array}$ \\
\hline
\end{tabular}


Table 2 continued

\begin{tabular}{|c|c|c|}
\hline $\begin{array}{l}\text { Teacher Mindfulness in } \\
\text { the Classroom Dimension }\end{array}$ & $\begin{array}{l}\text { CLASS-S Behavioral } \\
\text { Indicator }\end{array}$ & CLASS-S Description \\
\hline \multirow[t]{6}{*}{ Kind } & $\begin{array}{l}\text { Encouragement and } \\
\text { affirmation }\end{array}$ & $\begin{array}{l}\text { Recognition and } \\
\text { affirmation of effort; } \\
\text { encouragement of } \\
\text { persistence }\end{array}$ \\
\hline & Respect & $\begin{array}{l}\text { Respectful language; use of } \\
\text { each other's names; warm, } \\
\text { calm voice; listening to } \\
\text { each other; cooperation }\end{array}$ \\
\hline & Positive communications & $\begin{array}{l}\text { Positive comments; } \\
\text { positive expectations }\end{array}$ \\
\hline & $\begin{array}{l}\text { Responsive to academic } \\
\text { and social/emotional needs } \\
\text { and cues }\end{array}$ & $\begin{array}{l}\text { Individualized support; } \\
\text { reassurance and assistance; } \\
\text { adjusts pacing/wait time as } \\
\text { needed; re-engagement; } \\
\text { acknowledgement of } \\
\text { emotions and out-of-class } \\
\text { factors; timely response }\end{array}$ \\
\hline & Positive affect & $\begin{array}{l}\text { Smiling; laughter; } \\
\text { enthusiasm }\end{array}$ \\
\hline & Disrespect (r) & $\begin{array}{l}\text { Teasing; bullying; } \\
\text { humiliation and sarcasm; } \\
\text { exclusionary behavior; } \\
\text { inflammatory, } \\
\text { discriminatory, or } \\
\text { derogatory language or } \\
\text { behavior }\end{array}$ \\
\hline
\end{tabular}


Table 3

Descriptive Statistics for all Selected Items from Each Informant Source

\begin{tabular}{llcccc}
\hline \multirow{2}{*}{ Informant Source } & Item & Mean & SD & Min & Max \\
\hline Teacher Calm & Calm1 & 3.69 & .75 & 2.00 & 5.00 \\
& Calm2 & 3.59 & .75 & 1.00 & 5.00 \\
& Calm4 & 3.63 & .95 & 2.00 & 5.00 \\
Teacher Reactive & Calm5 & 3.52 & .85 & 1.00 & 5.00 \\
& rReactive1 & 3.49 & .90 & 1.00 & 5.00 \\
& rReactive2 & 3.72 & .70 & 2.00 & 5.00 \\
& rReactive3 & 4.00 & .87 & 2.00 & 5.00 \\
Teacher Clear & rReactive4 & 3.89 & .83 & 2.00 & 5.00 \\
& rReactive5 & 2.51 & .99 & 1.00 & 4.00 \\
& Clear1 & 3.95 & .78 & 2.00 & 5.00 \\
& Clear2 & 3.34 & .74 & 2.00 & 5.00 \\
Teacher & Clear3 & 3.46 & 1.00 & 1.00 & 5.00 \\
& Clear4 & 3.62 & .86 & 2.00 & 5.00 \\
& rDistracted1 & 3.71 & .81 & 2.00 & 5.00 \\
& & & & & \\
Teastracted & rDistracted2 & 3.80 & .83 & 1.00 & 5.00 \\
& rDistracted3 & 3.13 & .98 & 1.00 & 5.00 \\
& rDistracted4 & 3.65 & .98 & 1.00 & 5.00 \\
& rDistracted5 & 3.35 & 1.00 & 1.00 & 5.00 \\
& Kind1 & 4.31 & .66 & 3.00 & 5.00 \\
& Kind2 & 3.57 & .81 & 2.00 & 5.00 \\
& Kind3 & 3.66 & .85 & 1.00 & 5.00 \\
& Kind4 & 4.05 & .87 & 2.00 & 5.00 \\
& Kind5 & 4.32 & .64 & 3.00 & 5.00 \\
& rCritical2 & 3.32 & .79 & 2.00 & 5.00 \\
& rCritical3 & 3.44 & .97 & 1.00 & 5.00 \\
& rCritical4 & 4.03 & .83 & 2.00 & 5.00 \\
& & 4.08 & .93 & 1.00 & 5.00 \\
& 3.82 & .95 & 1.00 & 5.00 \\
\hline
\end{tabular}


Table 3 continued

\begin{tabular}{|c|c|c|c|c|c|}
\hline Informant Source & Item & Mean & $S D$ & Min & $\operatorname{Max}$ \\
\hline \multirow[t]{3}{*}{ Student Calm } & Calm1 & 4.05 & .55 & 3.00 & 5.00 \\
\hline & Calm2 & 4.13 & .55 & 2.89 & 5.00 \\
\hline & Calm3 & 3.96 & .52 & 2.32 & 5.00 \\
\hline \multirow[t]{3}{*}{ Student Reactive } & rReactive2 & 3.68 & .63 & 2.00 & 4.70 \\
\hline & rReactive3 & 3.49 & .67 & 2.00 & 5.00 \\
\hline & rReactive4 & 3.56 & .64 & 2.00 & 5.00 \\
\hline \multirow[t]{3}{*}{ Student Clear } & Clear1 & 4.43 & .47 & 3.00 & 5.00 \\
\hline & Clear2 & 3.92 & .57 & 2.67 & 5.00 \\
\hline & Clear3 & 3.86 & .57 & 2.25 & 5.00 \\
\hline \multirow{3}{*}{$\begin{array}{l}\text { Student } \\
\text { Distracted }\end{array}$} & rDistracted1 & 3.76 & .48 & 2.67 & 5.00 \\
\hline & rDistracted2 & 4.23 & .48 & 3.00 & 5.00 \\
\hline & rDistracted3 & 3.92 & .48 & 2.67 & 5.00 \\
\hline \multirow[t]{3}{*}{ Student Kind } & Kind4 & 3.46 & .73 & 2.00 & 5.00 \\
\hline & Kind5 & 3.75 & .69 & 1.00 & 5.00 \\
\hline & Kind 7 & 4.31 & .49 & 2.71 & 5.00 \\
\hline \multirow[t]{3}{*}{ Student Critical } & rCritical1 & 4.33 & .51 & 2.83 & 5.00 \\
\hline & rCritical2 & 4.33 & .45 & 3.43 & 5.00 \\
\hline & rCritical3 & 4.27 & .51 & 2.67 & 5.00 \\
\hline
\end{tabular}


Table 3 continued

\begin{tabular}{llllll}
\hline $\begin{array}{l}\text { Informant } \\
\text { Source }\end{array}$ & Item & Mean & $S D$ & Min & Max \\
\hline Observer Calm & Redirection & 4.08 & .85 & 1.50 & 5.00 \\
& Proactive & 4.10 & .78 & 1.75 & 5.00 \\
rPunitive Con & 4.90 & .23 & 4.00 & 5.00 \\
Observer Clear & Learn Time & 4.34 & .57 & 2.75 & 5.00 \\
& Routines & 4.40 & .60 & 2.38 & 5.00 \\
& Address Prob & 3.83 & .63 & 1.86 & 5.00 \\
& Aware & 3.91 & .64 & 2.63 & 5.00 \\
& Expectations & 4.47 & .68 & 2.38 & 5.00 \\
& Preparation & 4.65 & .43 & 3.25 & 5.00 \\
& Build Respon & 2.48 & .68 & 1.00 & 4.13 \\
Ebserver Kind & Encourage & 2.18 & .73 & 1.00 & 3.88 \\
& Respect & 3.89 & .70 & 2.13 & 5.00 \\
& Pos Comm & 2.97 & .80 & 1.50 & 5.00 \\
& Responsive & 3.80 & .60 & 2.50 & 5.00 \\
& Pos Affect & 3.28 & .65 & 1.88 & 4.75 \\
& rDisrespect & 4.76 & .43 & 2.88 & 5.00 \\
\hline
\end{tabular}




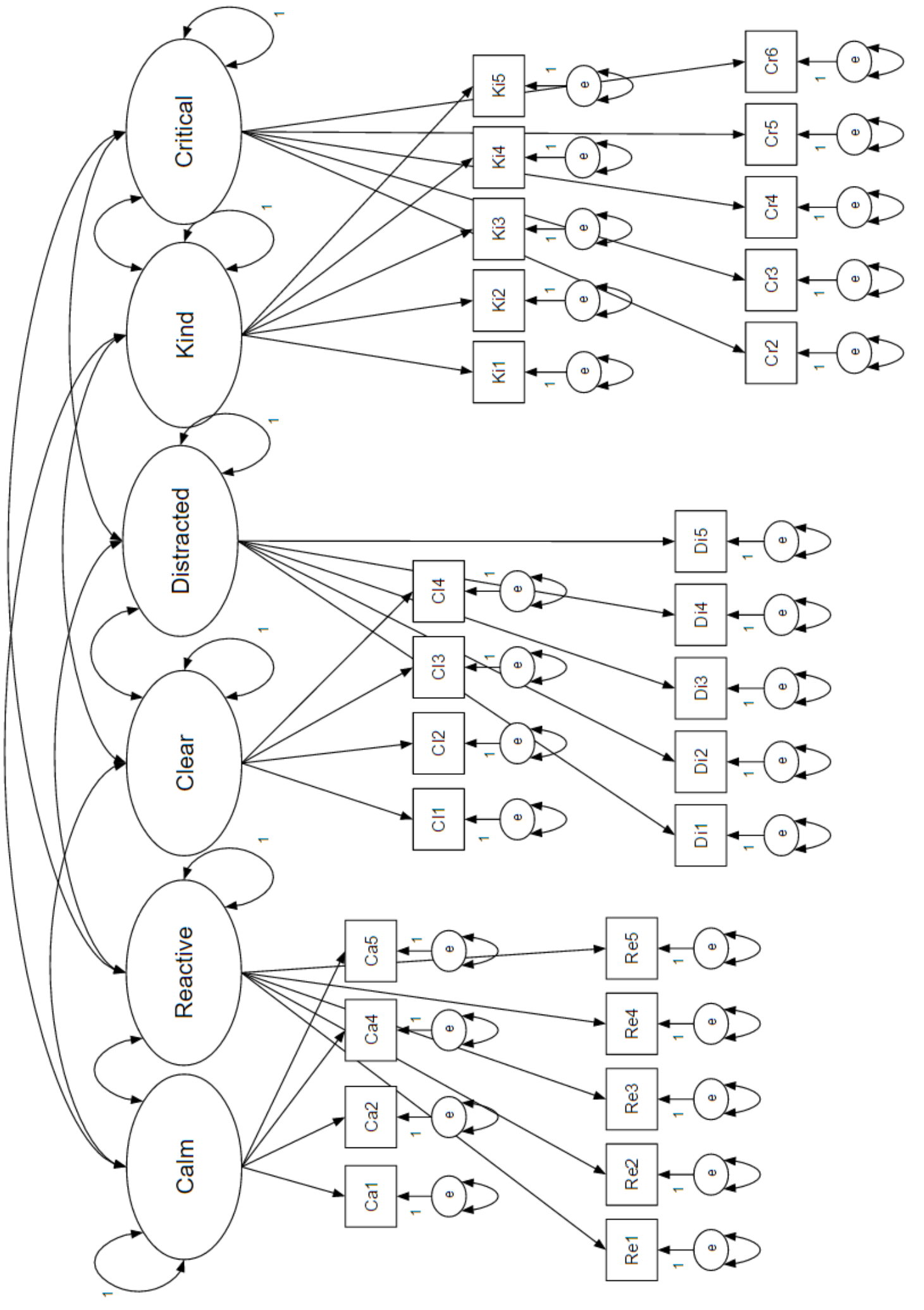

Figure 2. Proposed 6-factor CFA model for teacher reports. 


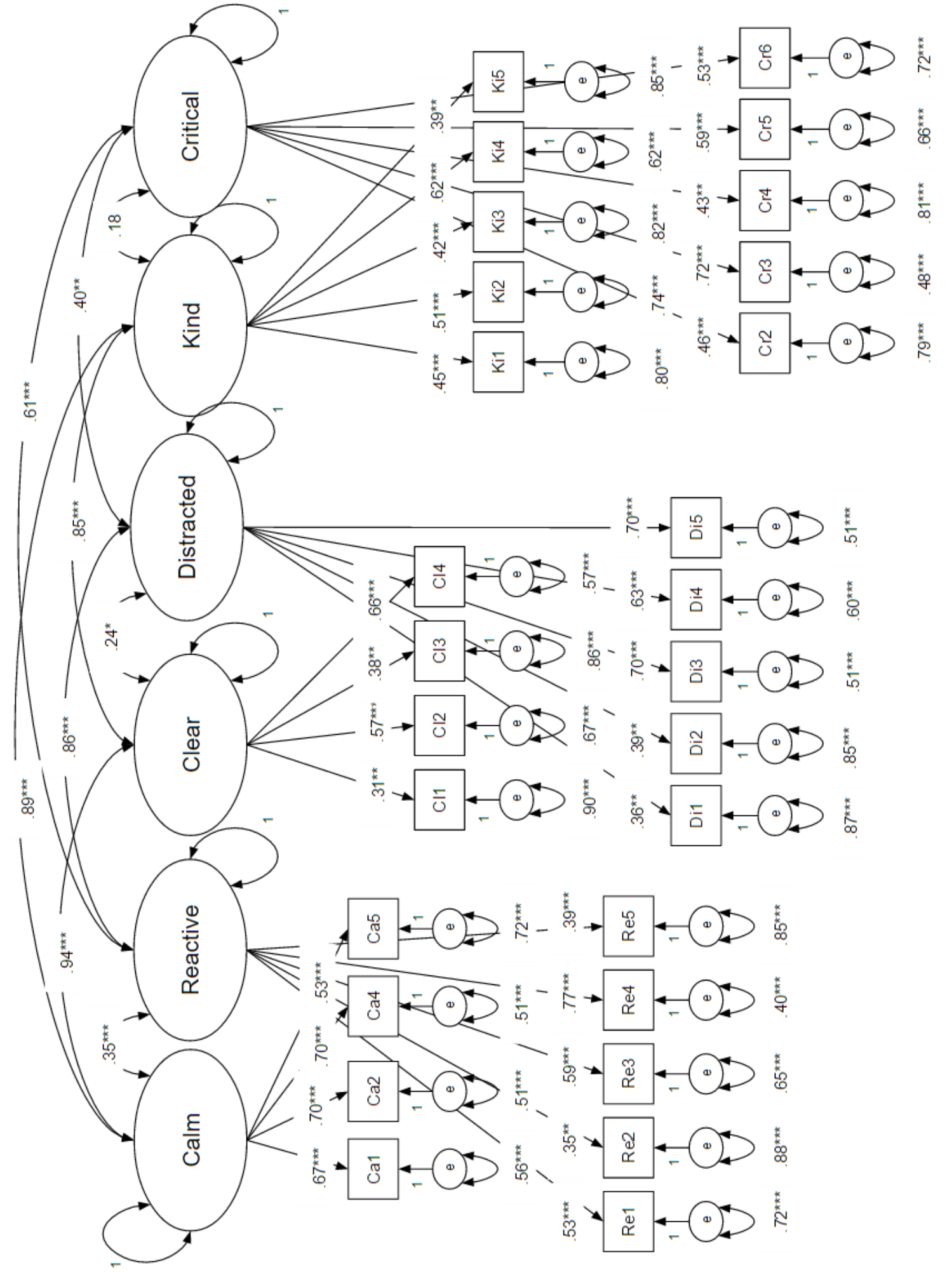

Figure 3. CFA 6-factor model for teacher reports. $\chi^{2}(341)=636.21, p=0.00, \mathrm{CFI}=.58$, $\mathrm{TLI}=.54, \mathrm{RMSEA}=.12$. 
Table 4

Standardized Residuals for 6-Factor Teacher Report CFA

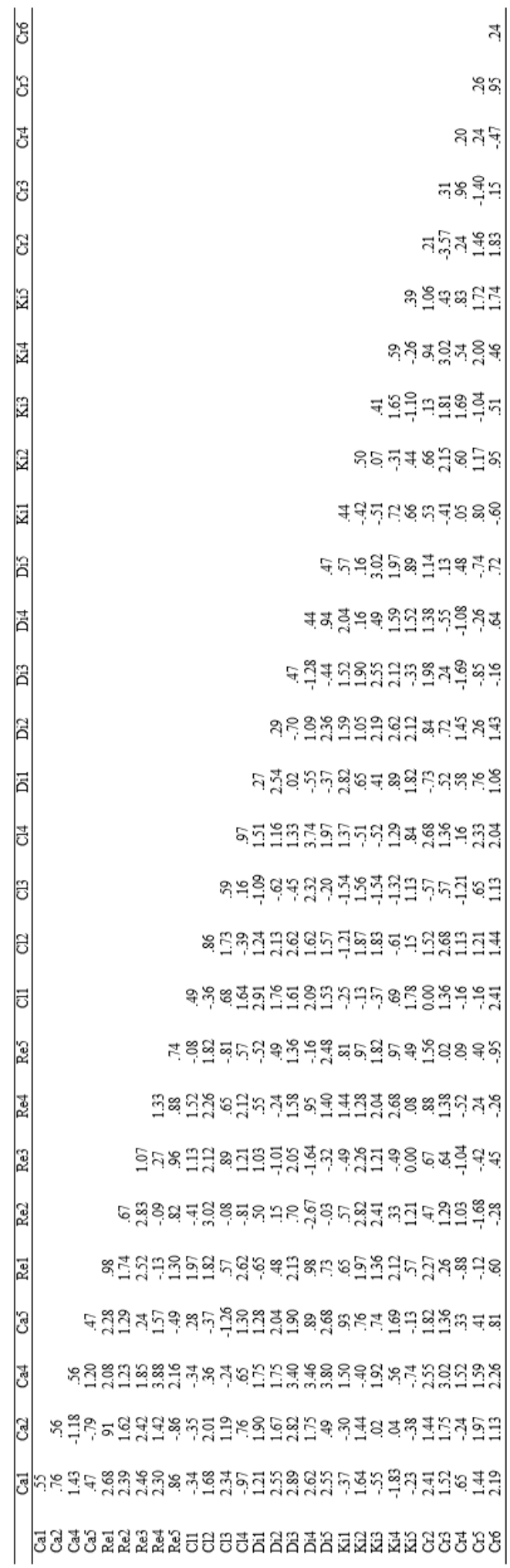




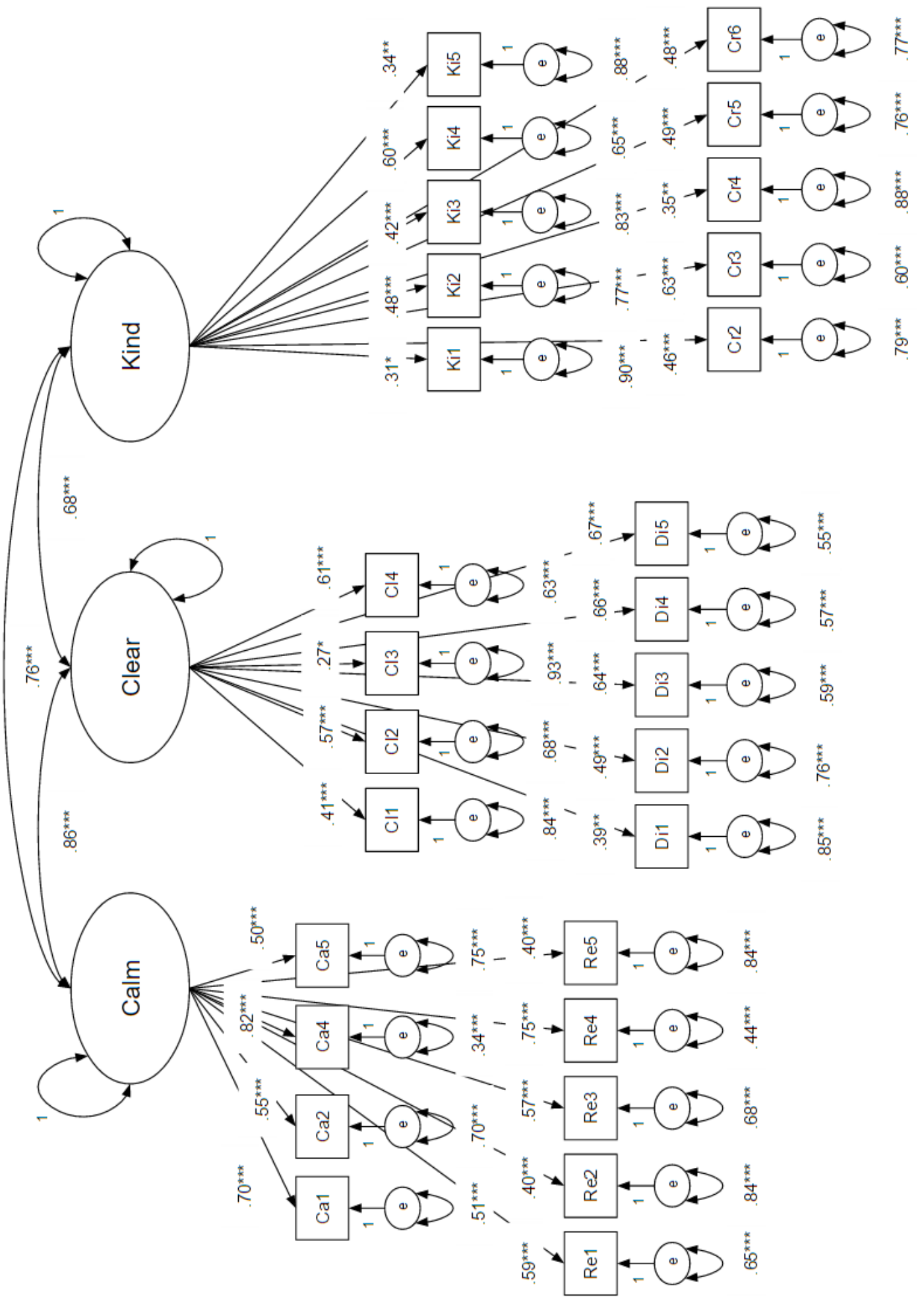

Figure 4. CFA 3-factor model for teacher reports. $\chi^{2}(347)=661.46, p=0.00$, CFI $=.55$, $\mathrm{TLI}=.51, \mathrm{RMSEA}=.12$. 
Table 5

Standardized Residuals for 3-Factor Teacher Report CFA

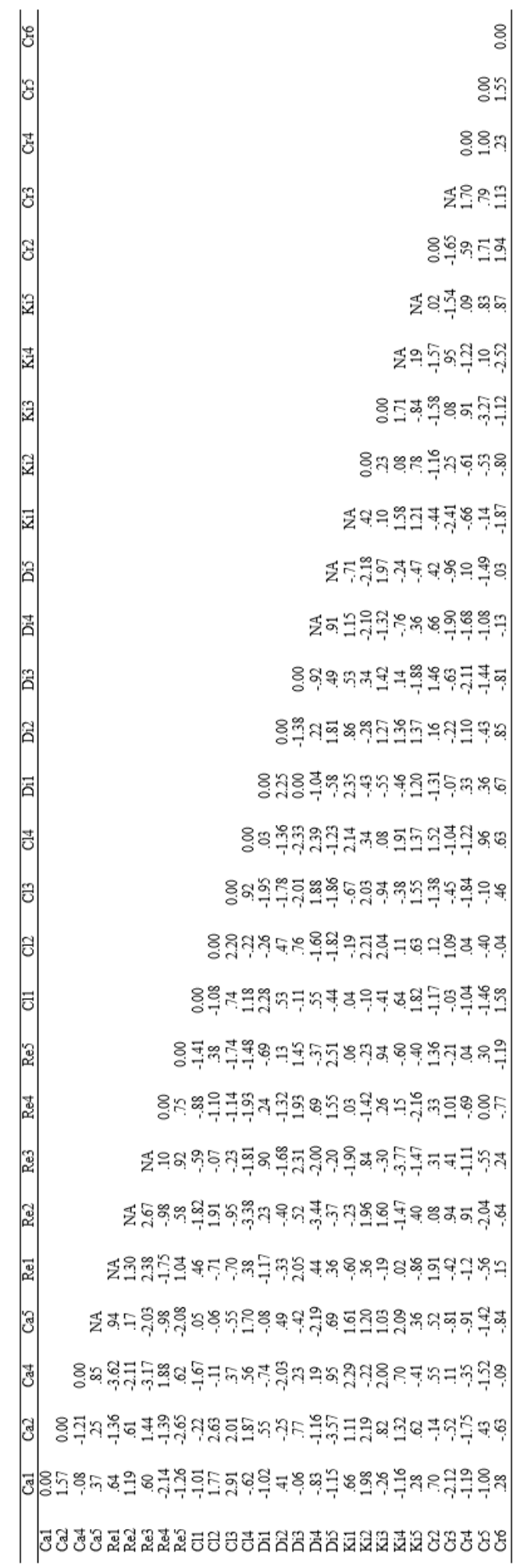


Table 6

Chi-Square Difference Test for 6-vs. 3-Factor Teacher Report CFAs

\begin{tabular}{lccccc}
\hline & Df & AIC & BIC & $\chi^{2}$ & $\begin{array}{c}\chi^{2} \\
\text { difference }\end{array}$ \\
\hline 6-factor CFA & 341 & 4285.1 & 4427.4 & 636.21 & \\
3-factor CFA & 347 & 4298.5 & 4427.5 & 661.46 & $25.25 * * *$ \\
\hline$* * * p<.001$ & & & & &
\end{tabular}




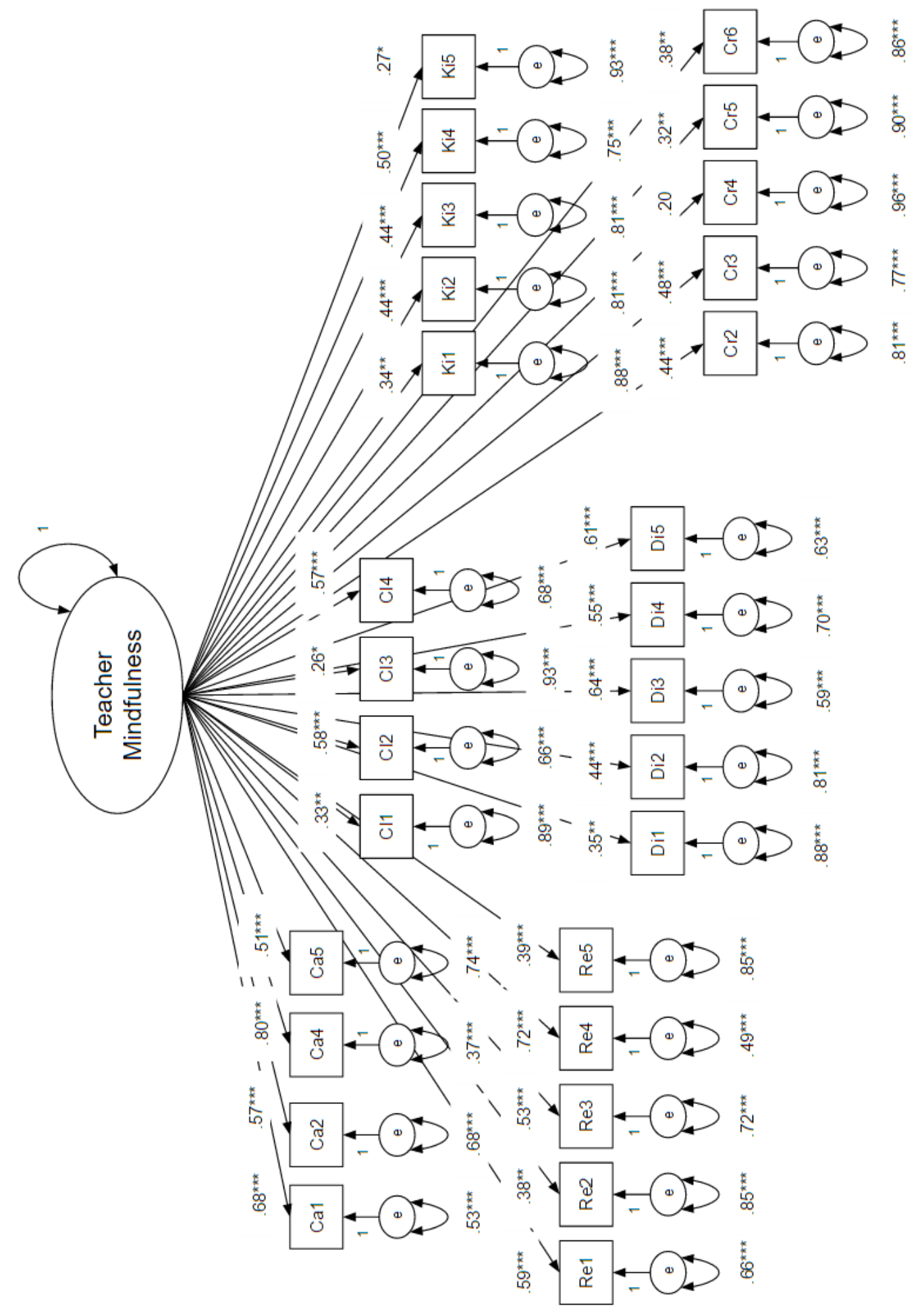

Figure 5. CFA 1-factor alternative model for teacher reports. $\chi^{2}(350)=685.19, p=0.00$, $\mathrm{CFI}=.53, \mathrm{TLI}=.49, \mathrm{RMSEA}=.12$. 
Table 7

Standardized Residuals for 1-Factor Teacher Report CFA

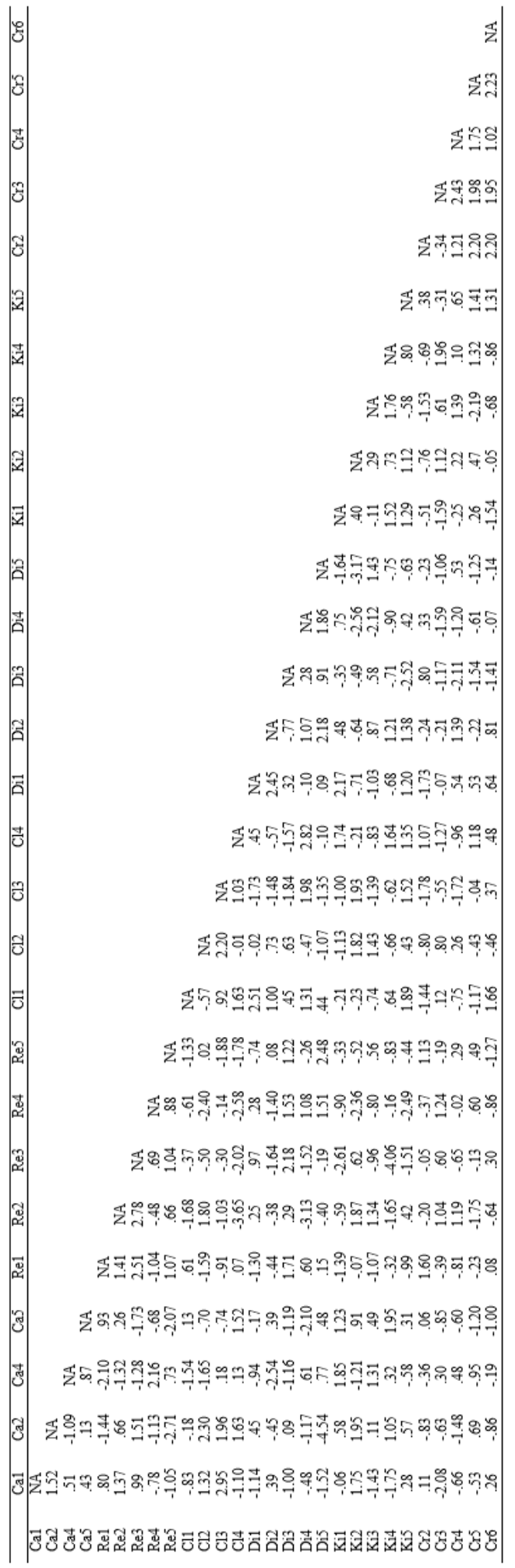


Table 8

Chi-Square Difference Test for 3-vs. 1-Factor Teacher Report CFAs

\begin{tabular}{lccccc}
\hline & Df & AIC & BIC & $\chi^{2}$ & $\begin{array}{c}\chi^{2} \\
\text { difference }\end{array}$ \\
\hline 3-factor CFA & 347 & 4298.3 & 4427.5 & 661.46 & \\
1 -factor CFA & 350 & 4316.0 & 4438.7 & 685.19 & $23.73 * * *$ \\
\hline$* * * p<.001$ & & & & &
\end{tabular}




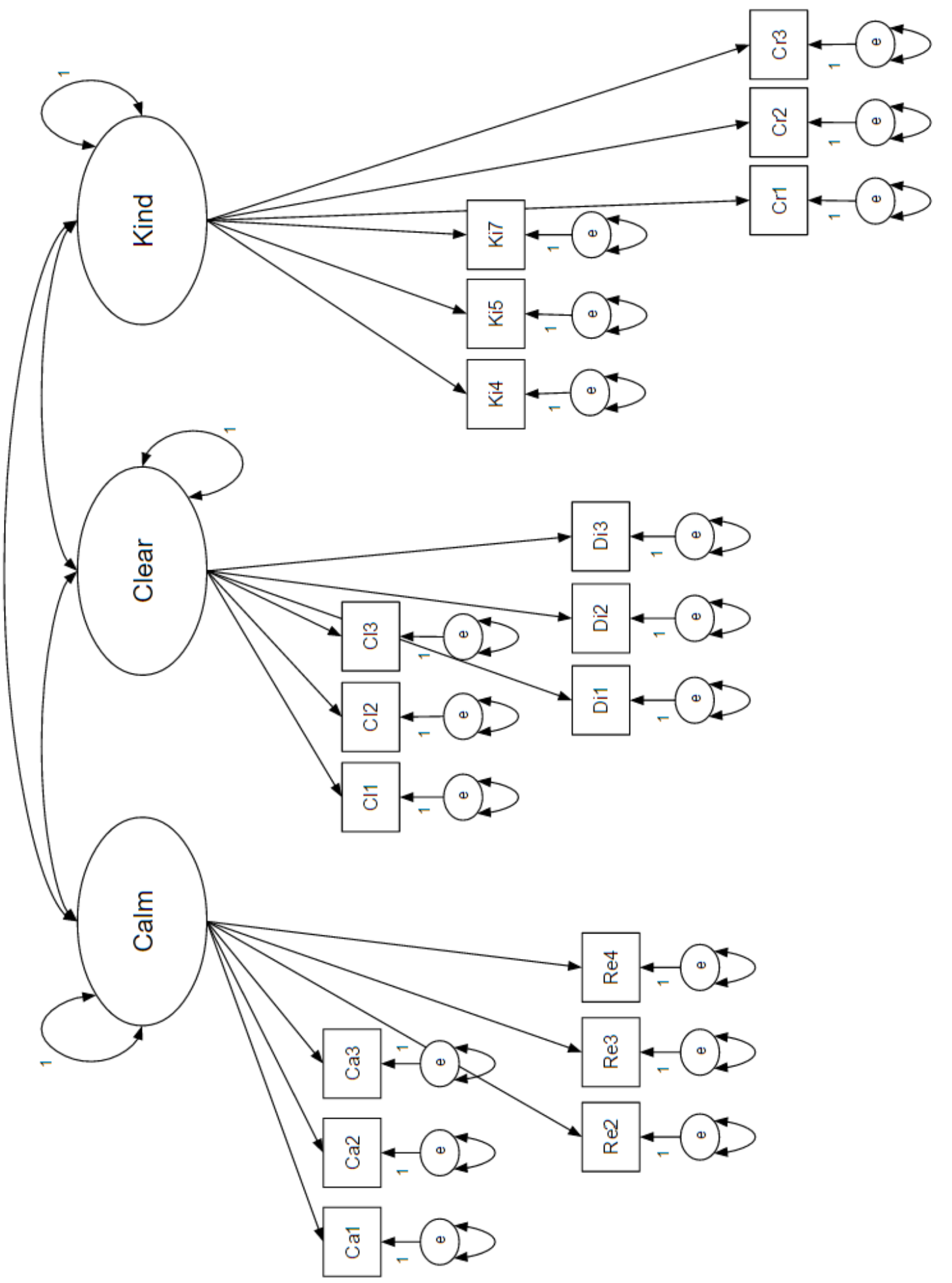

Figure 6. Proposed CFA model for student reports. 


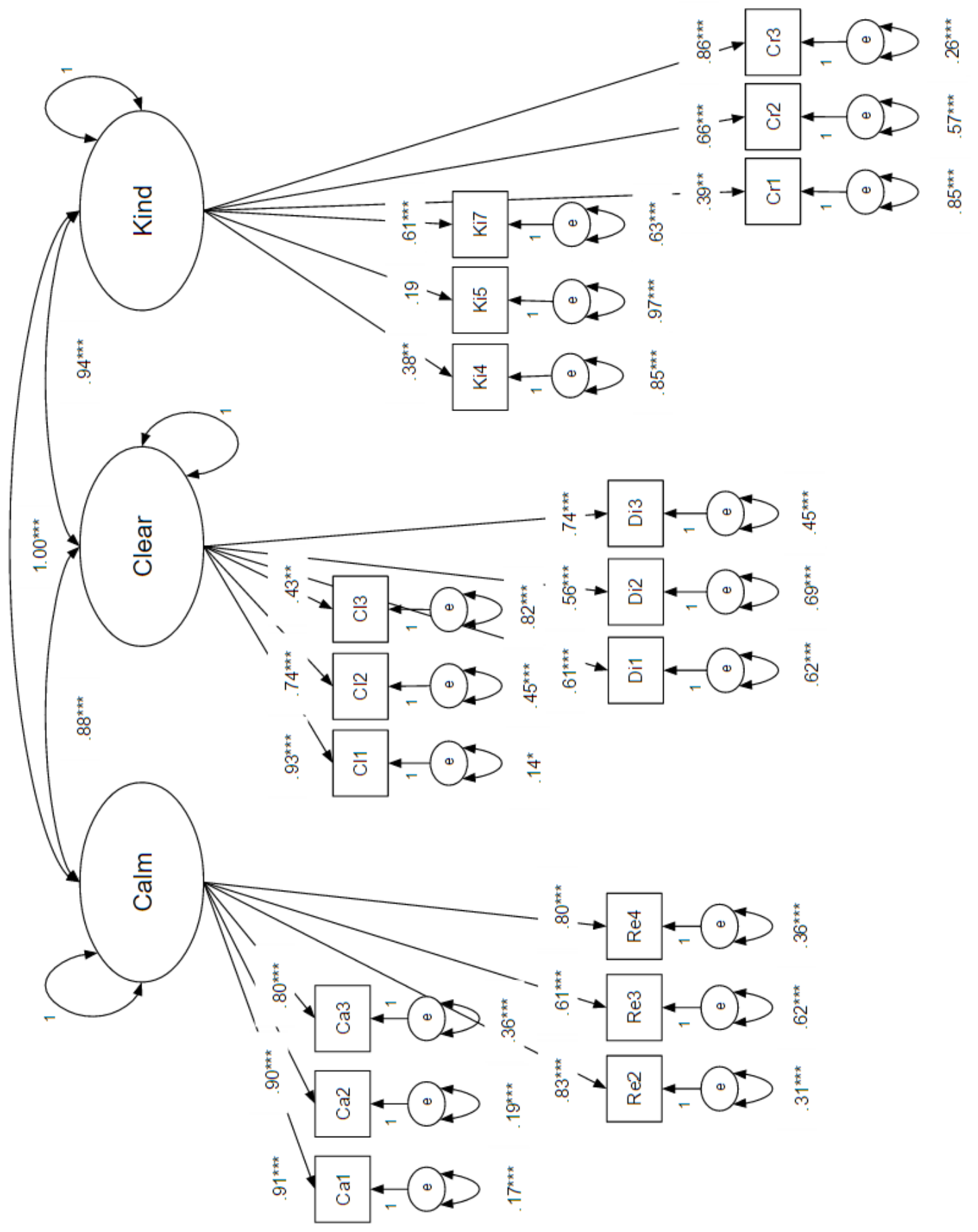

Figure 7. CFA model for student reports. $\chi^{2}(132)=326.86, p=0.00$, CFI $=.71$, TLI $=$ $.66, \mathrm{RMSEA}=.18$. 
Table 9

Standardized Residuals for 3-Factor Student Report CFA

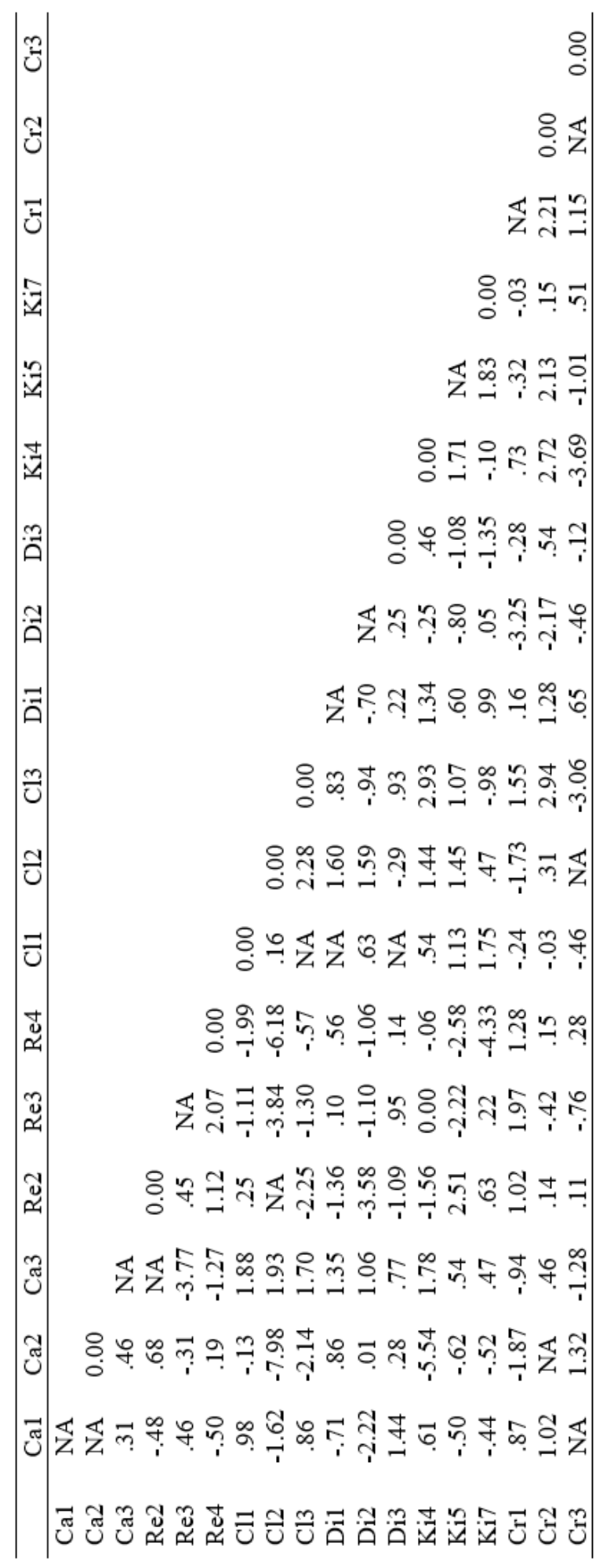




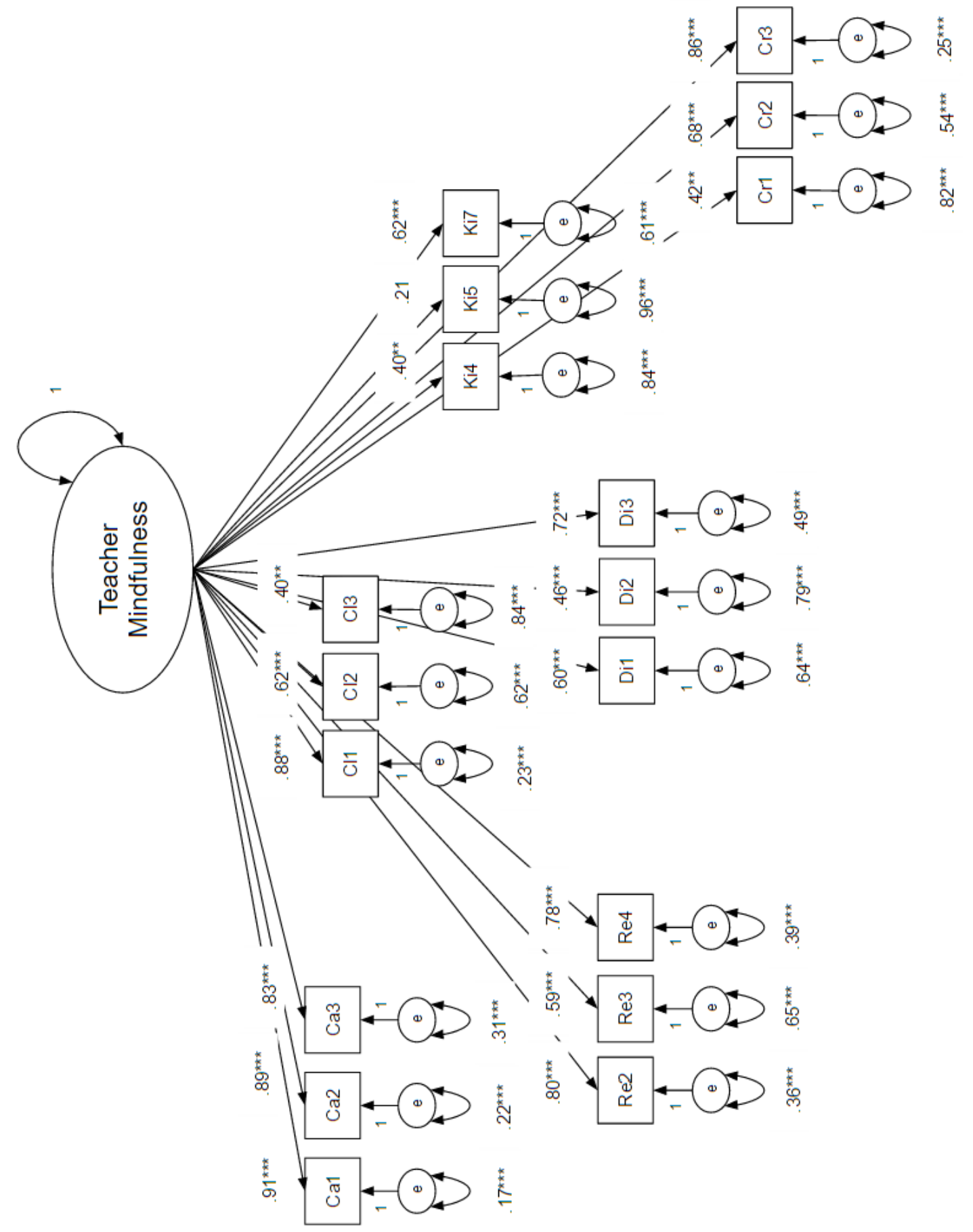

Figure 8. CFA 1-factor alternative model for student reports. $\chi^{2}(135)=345.37, p=0.00$, $\mathrm{CFI}=.68, \mathrm{TLI}=.64, \mathrm{RMSEA}=.18$. 
Table 10

Standardized Residuals for 1-Factor Student Report CFA

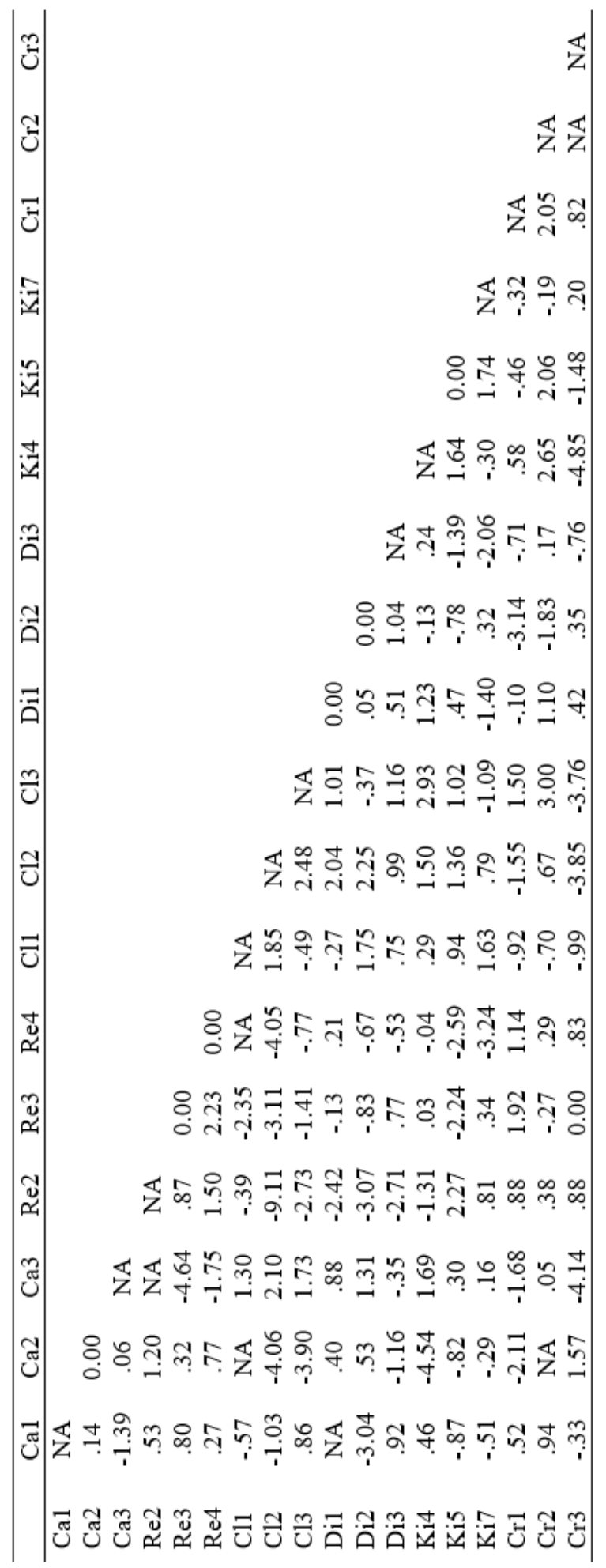


Table 11

Chi-Square Difference Test for Student Report CFAs

\begin{tabular}{lccccc}
\hline & Df & AIC & BIC & $\chi^{2}$ & $\begin{array}{c}\chi^{2} \\
\text { difference }\end{array}$ \\
\hline 3-factor CFA & 132 & 1390.5 & 1462.7 & 326.86 & \\
1 -factor CFA & 135 & 1403.0 & 1469.6 & 345.37 & $18.51 * * *$ \\
\hline$* * * p<.001$ & & & & &
\end{tabular}




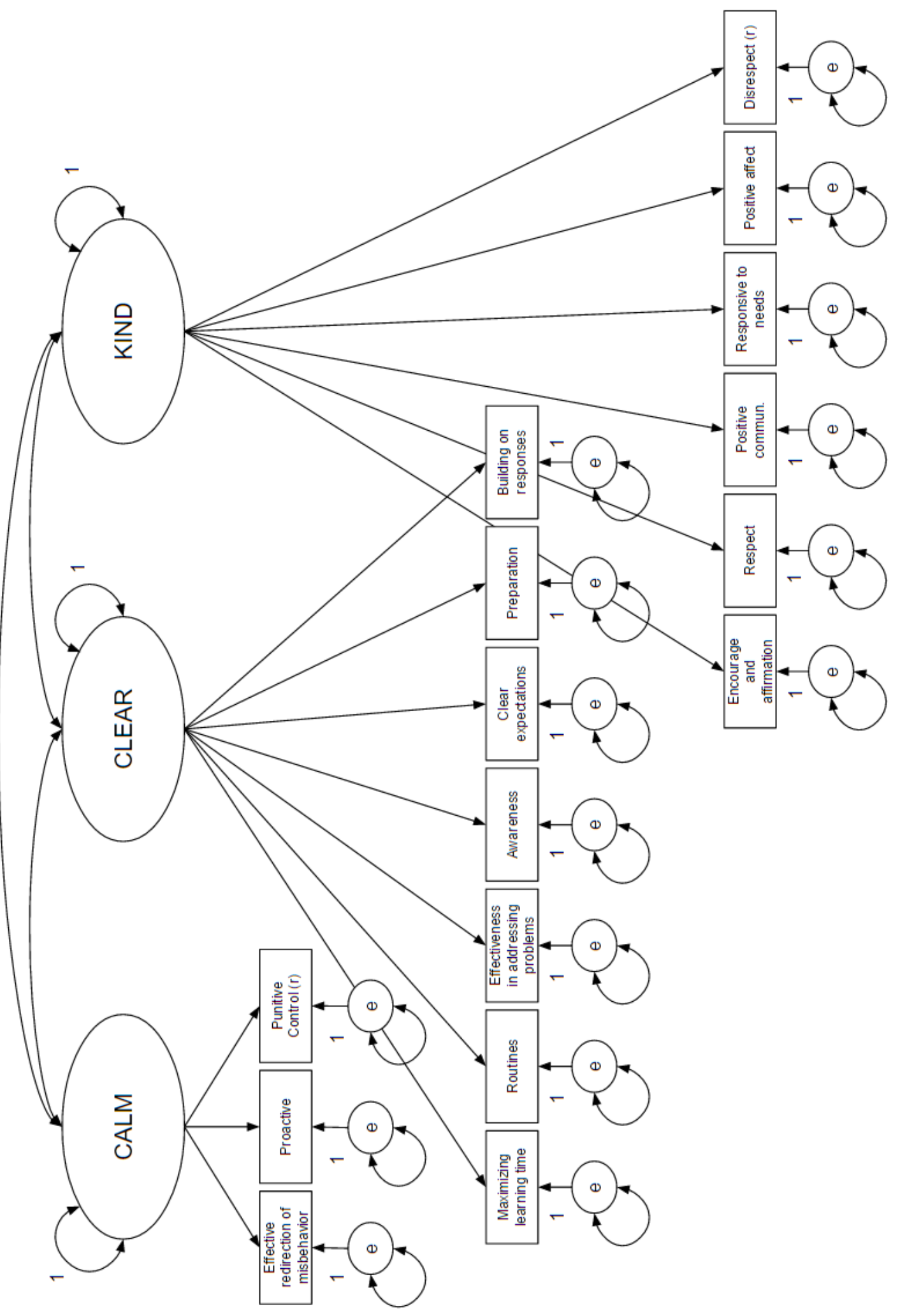

Figure 9. Proposed CFA model for observer reports. 


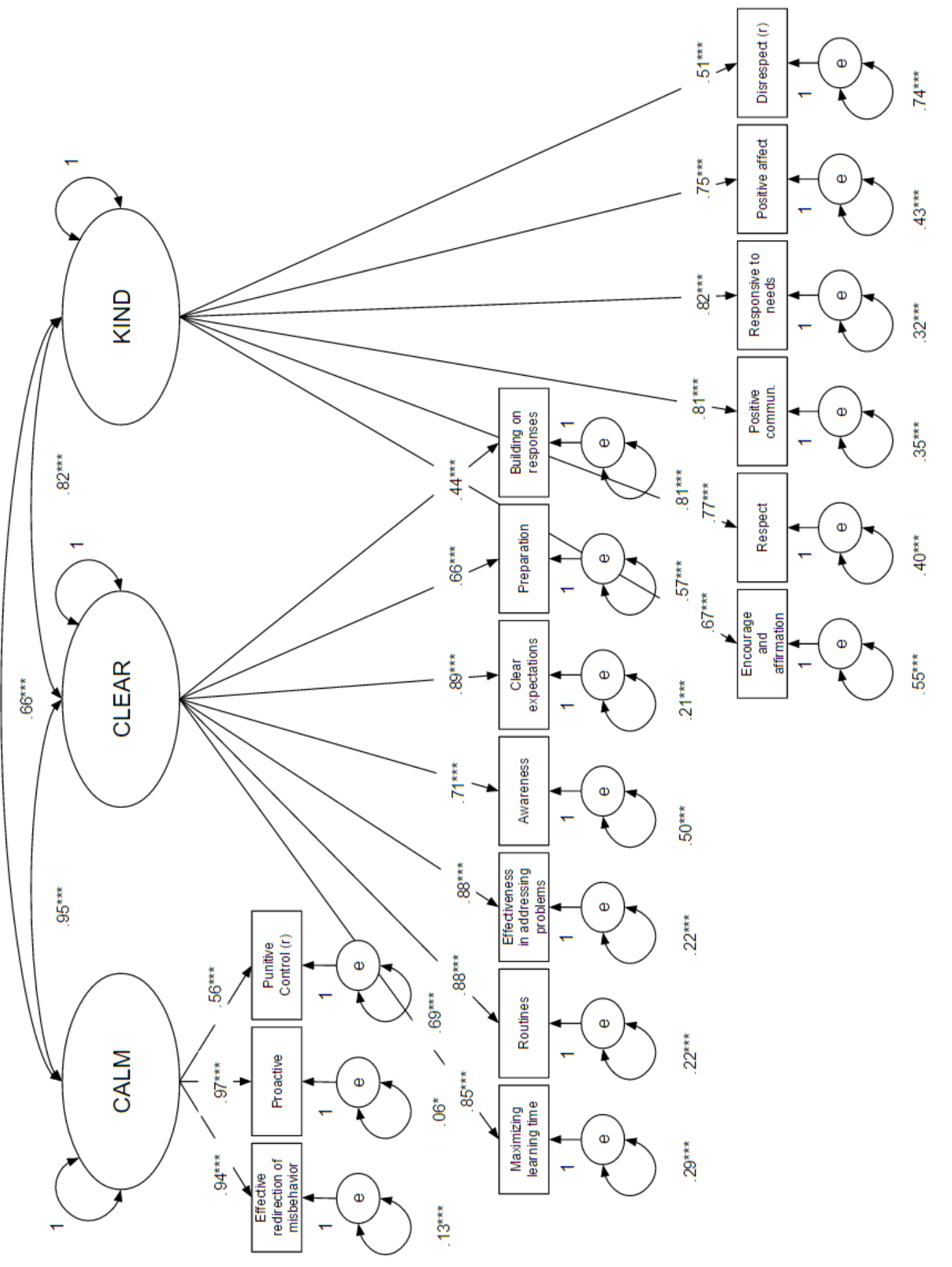

Figure 10. CFA model for observer reports. $\chi^{2}(101)=285.48, p=0.00$, CFI $=.79, \mathrm{TLI}=$ .76, RMSEA $=.17$. 
Table 12

Standardized Residuals for 3-Factor Observer Report CFA

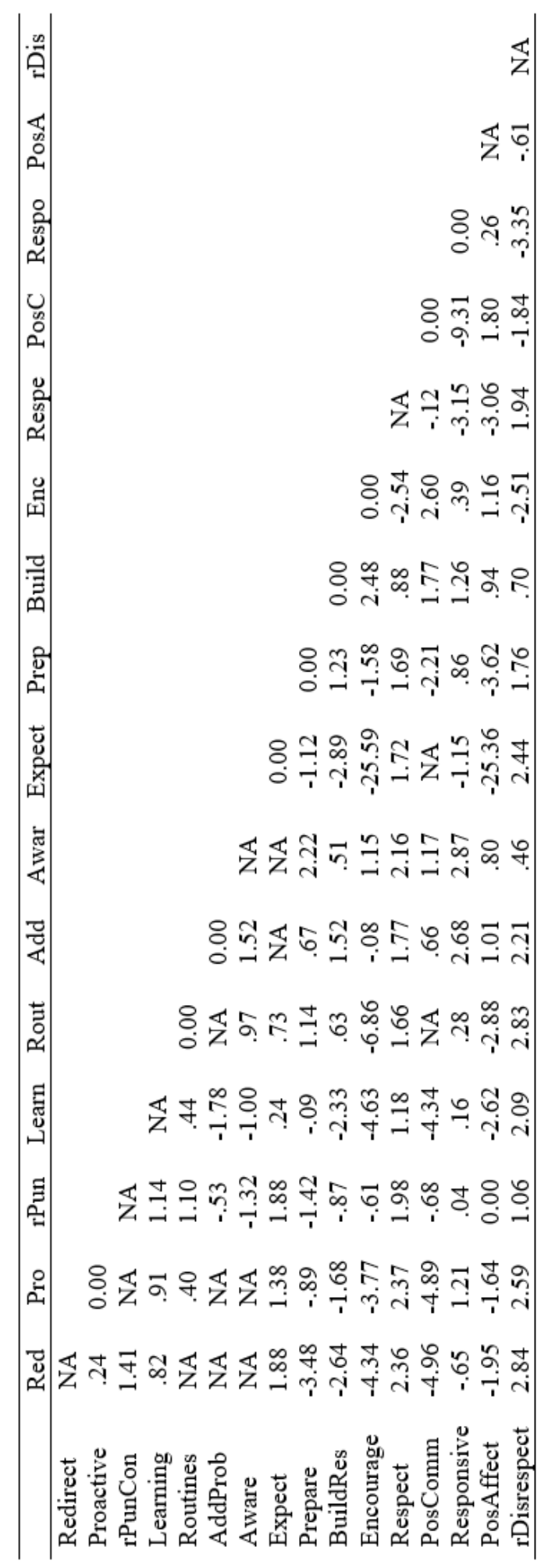




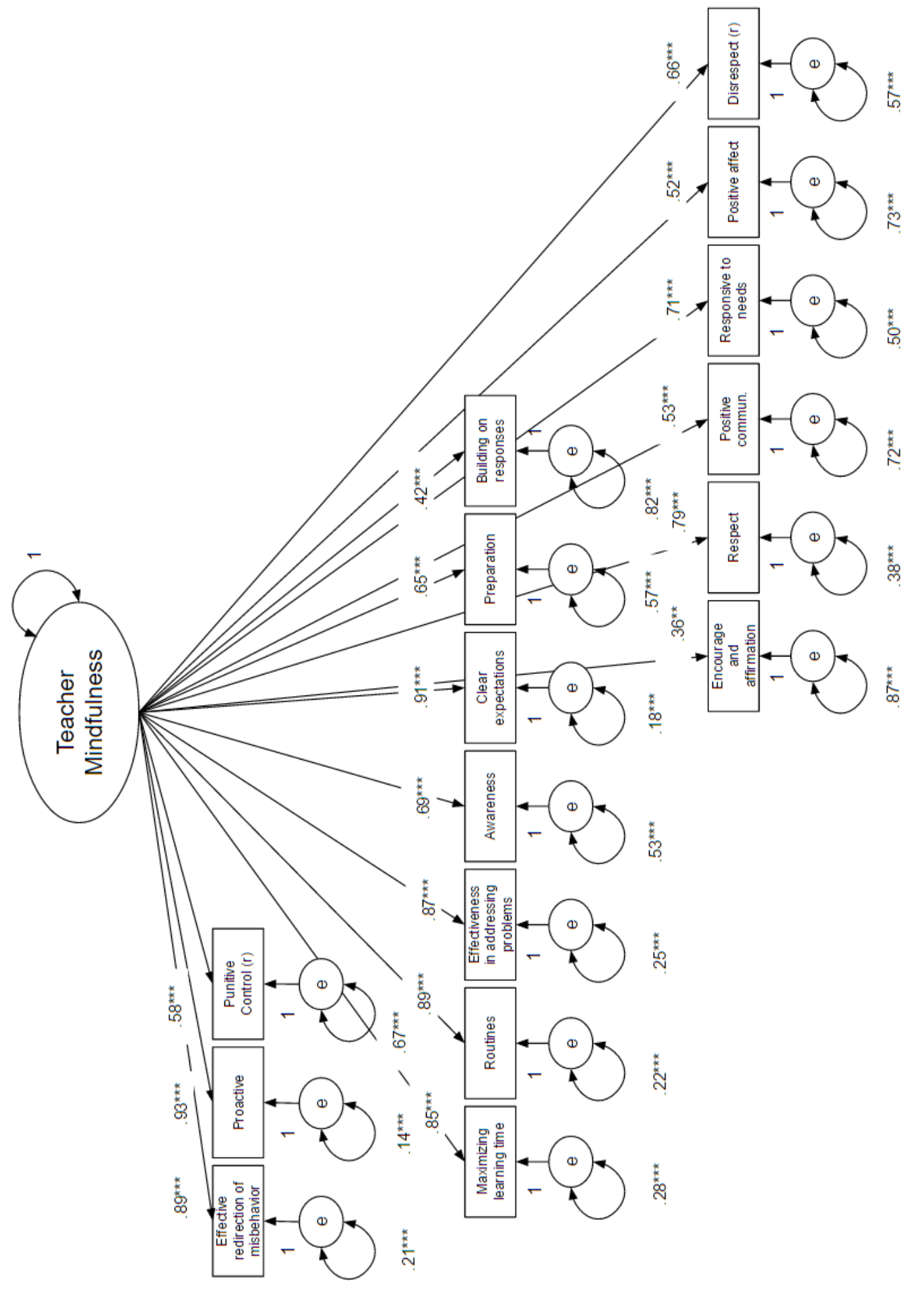

Figure 11. CFA 1-factor alternative model for observer reports. $\chi^{2}(104)=345.60, p=$ $0.00, \mathrm{CFI}=.73, \mathrm{TLI}=.69, \mathrm{RMSEA}=.19$. 
Table 13

Standardized Residuals for 1-Factor Observer Report CFA

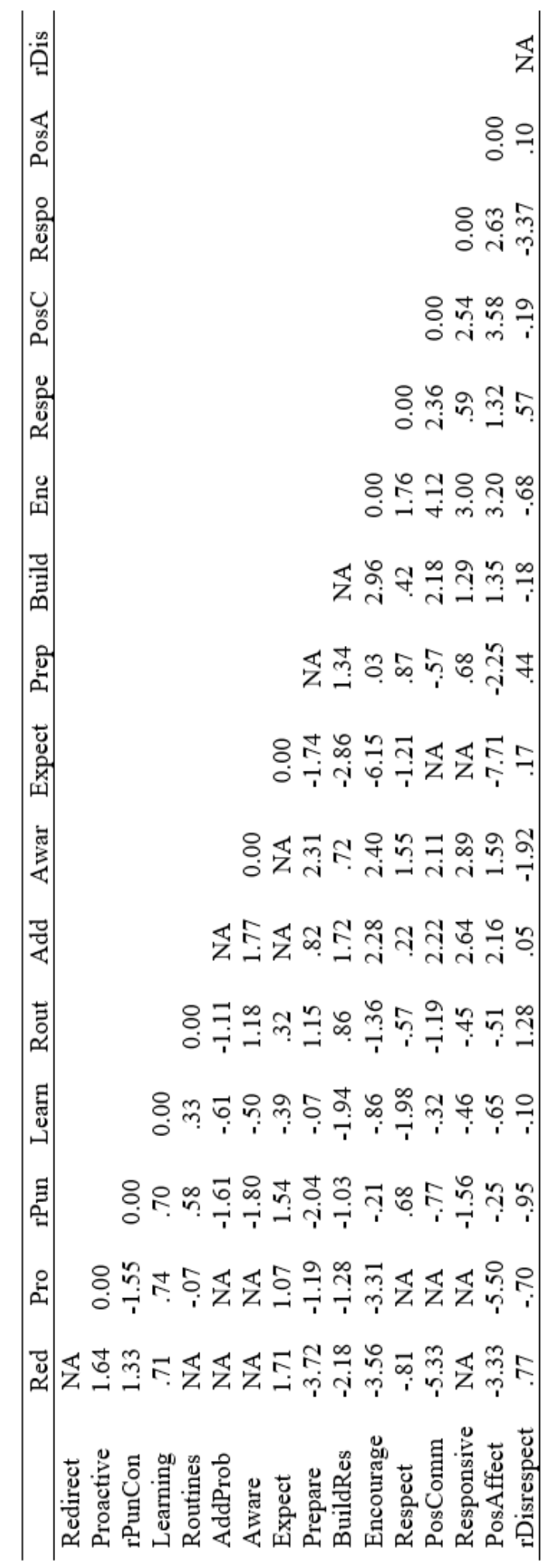


Table 14

Chi-Square Difference Test for Observer Report CFAs

\begin{tabular}{lccccc}
\hline & Df & AIC & BIC & $\chi^{2}$ & $\begin{array}{c}\chi^{2} \\
\text { difference }\end{array}$ \\
\hline 3-factor CFA & 101 & 1126.0 & 1200.5 & 285.48 & \\
1 -factor CFA & 104 & 1180.1 & 1248.2 & 345.60 & $60.12 * * *$ \\
\hline$* * * p<.001$ & & & & &
\end{tabular}


Table 15

Descriptive Statistics for Composite Variables of Calm, Clear, and Kind from Each Informant Source

\begin{tabular}{|c|c|c|c|c|c|c|}
\hline & Mean & $S D$ & Min & Max & $\begin{array}{c}\text { Cronbach's } \\
\alpha\end{array}$ & $\begin{array}{l}\text { Number of } \\
\text { items }\end{array}$ \\
\hline $\begin{array}{l}\text { T Report } \\
\text { Calm }\end{array}$ & 3.56 & .55 & 2.44 & 4.67 & .83 & 9 \\
\hline $\begin{array}{l}\text { T Report } \\
\text { Clear }\end{array}$ & 3.56 & .53 & 2.56 & 4.78 & .77 & 9 \\
\hline $\begin{array}{l}\text { T Report } \\
\text { Kind }\end{array}$ & 3.86 & .45 & 3.00 & 4.90 & .73 & 10 \\
\hline $\begin{array}{l}\text { O Report } \\
\text { Calm }\end{array}$ & 4.36 & .58 & 2.67 & 5.00 & .86 & 3 \\
\hline $\begin{array}{l}\text { O Report } \\
\text { Clear }\end{array}$ & 4.01 & .48 & 2.48 & 4.75 & .91 & 7 \\
\hline $\begin{array}{l}\text { O Report } \\
\text { Kind }\end{array}$ & 3.48 & .51 & 2.23 & 4.5 & .86 & 6 \\
\hline $\begin{array}{l}\text { S Report } \\
\text { Calm }\end{array}$ & 3.81 & .50 & 2.63 & 4.67 & .92 & 6 \\
\hline $\begin{array}{l}\text { S Report } \\
\text { Clear }\end{array}$ & 4.02 & .38 & 3.14 & 5.00 & .85 & 6 \\
\hline $\begin{array}{l}\text { S Report } \\
\text { Kind }\end{array}$ & 4.08 & .37 & 3.25 & 4.65 & .75 & 6 \\
\hline
\end{tabular}




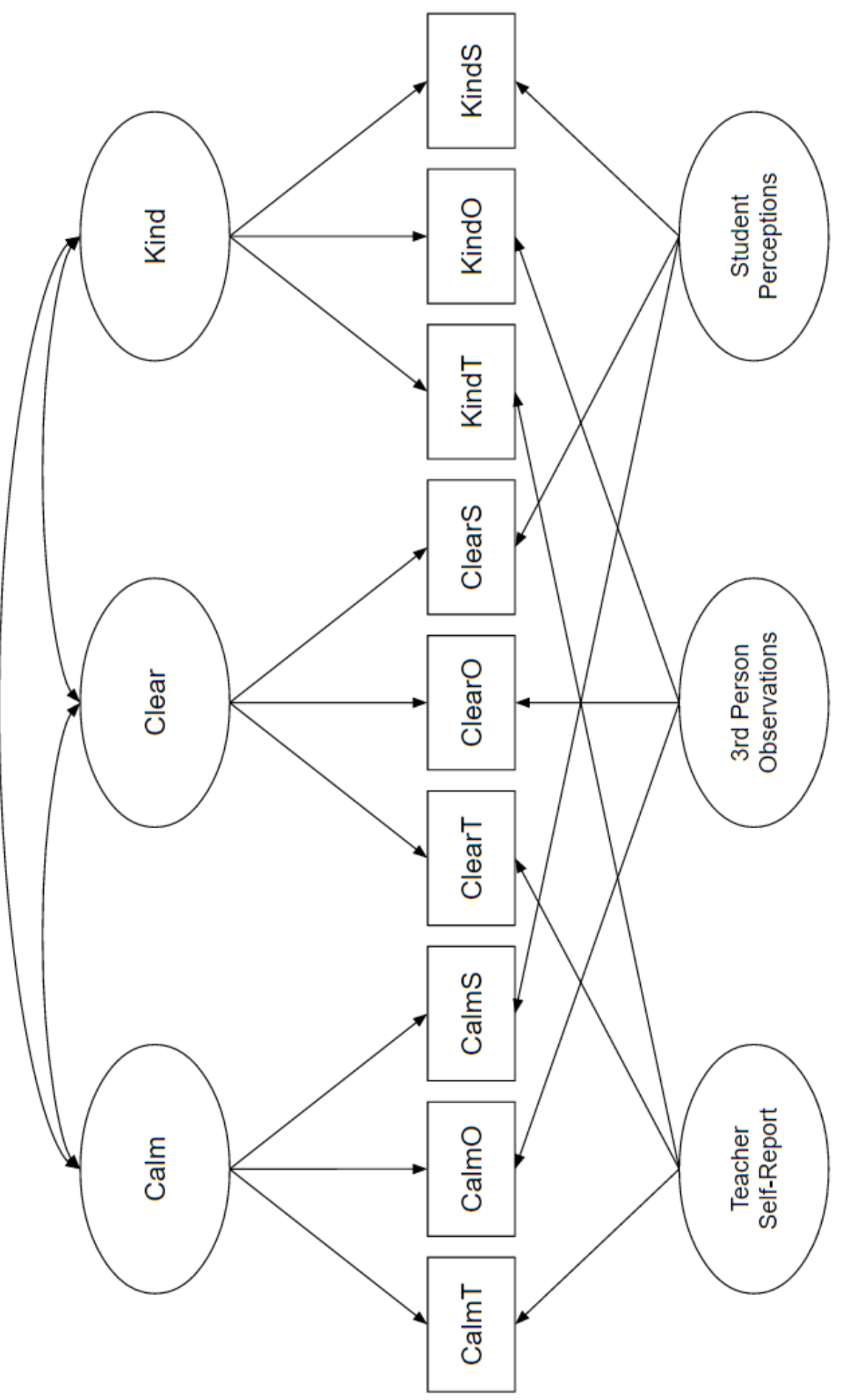

Figure 12. Proposed MTMI CFA model. 


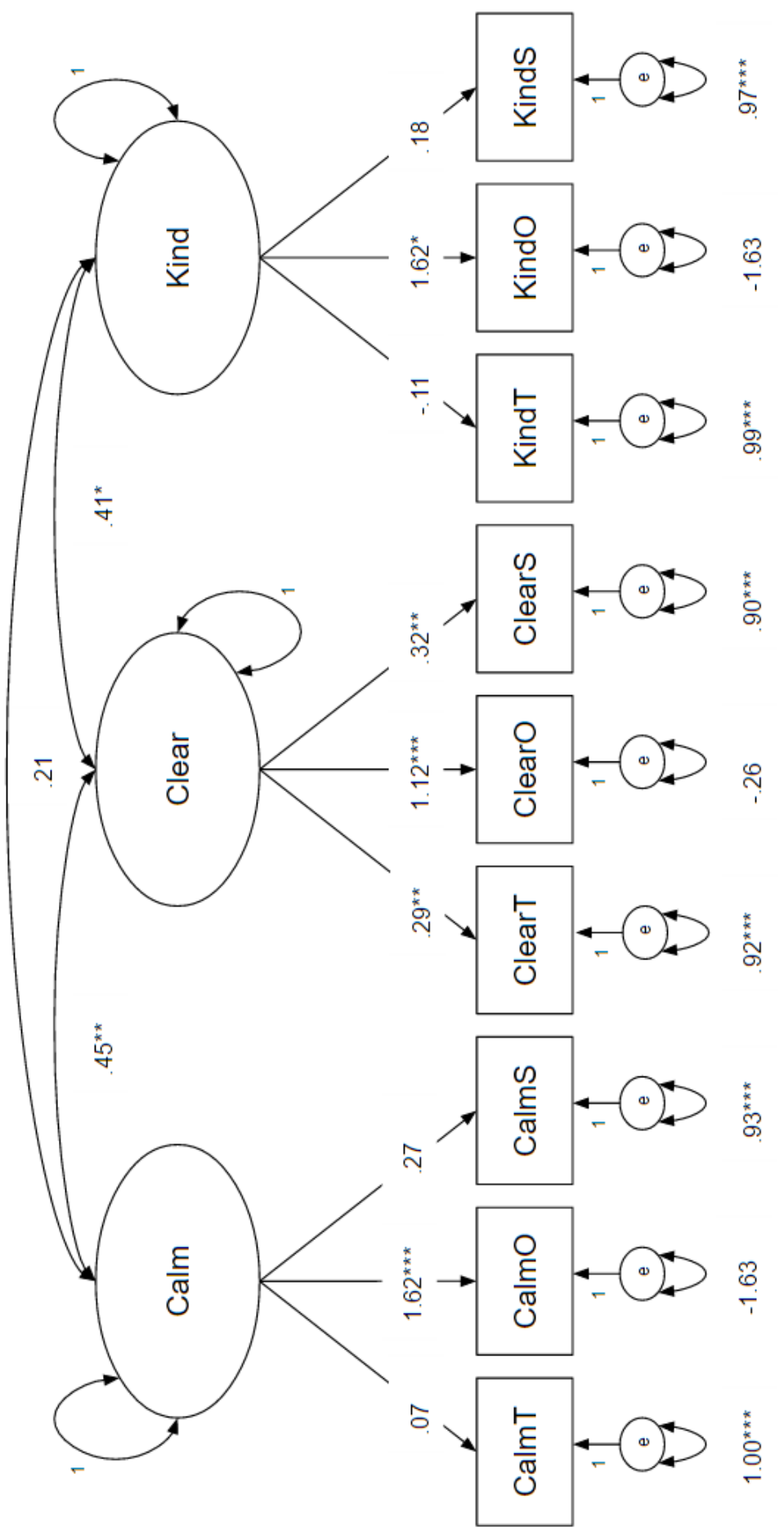

Figure 13. Calm, clear, kind CFA model from each informant. $\chi^{2}(24)=225.94, p=0.00$, $\mathrm{CFI}=.49, \mathrm{TLI}=.23, \mathrm{RMSEA}=.35$. 
Table 16

Standardized Residuals for Calm, Clear, and Kind CFA

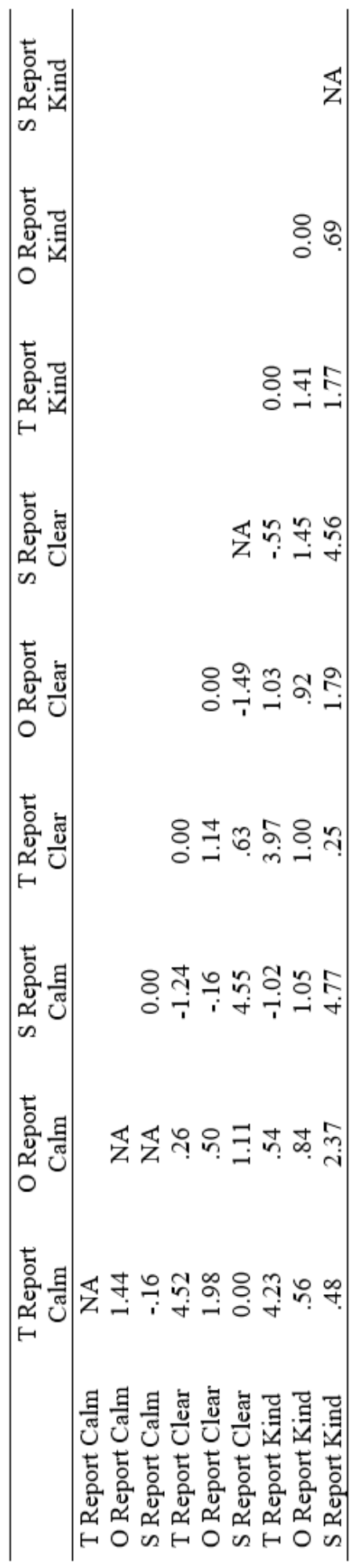



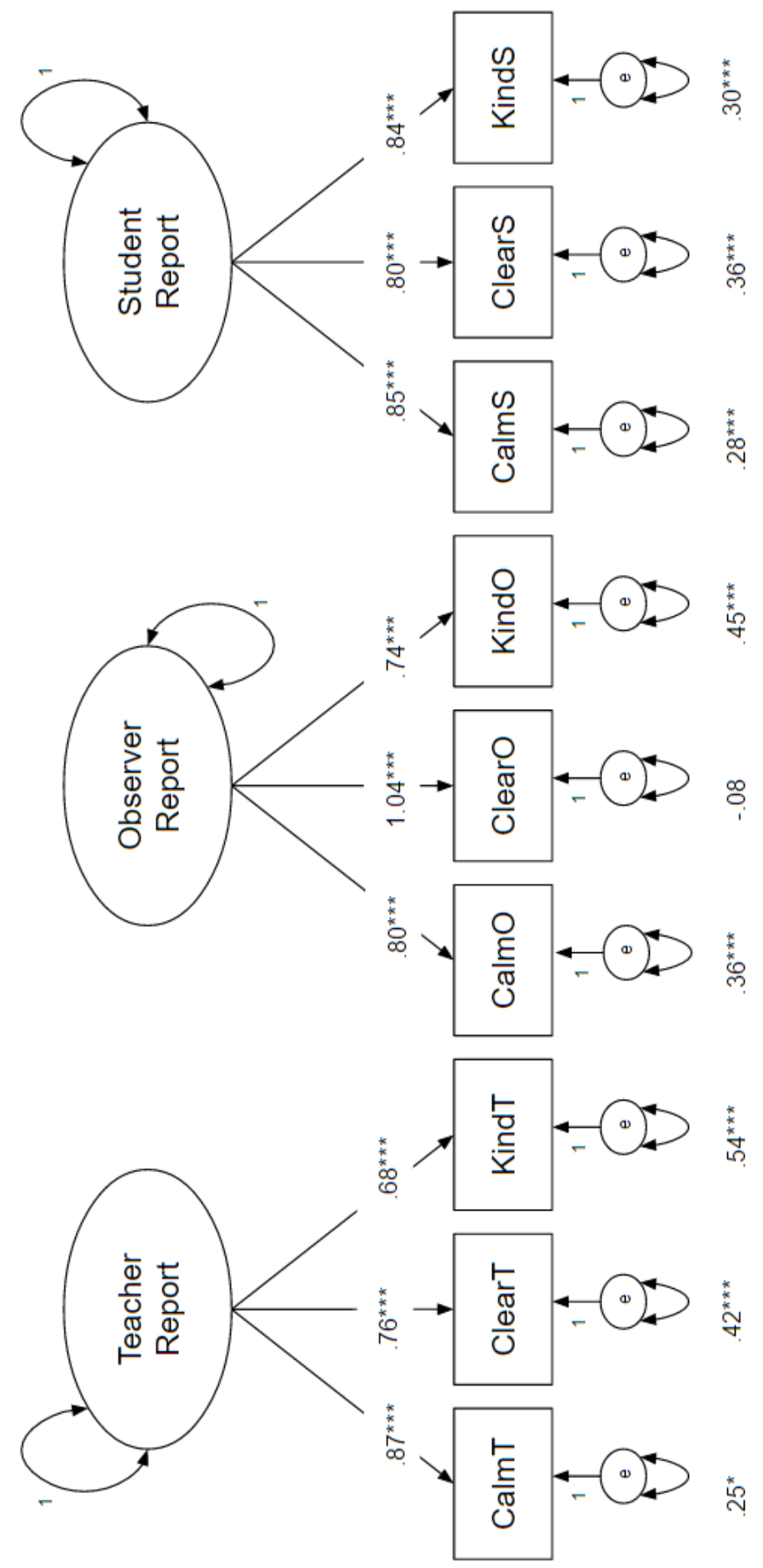

Figure 14. Method effects CFA model. $\chi^{2}(27)=110.90, p=0.00, \mathrm{CFI}=.79, \mathrm{TLI}=.72$, RMSEA $=.21$ 
Table 17

Standardized Residuals for Teacher, Observer, and Student CFA

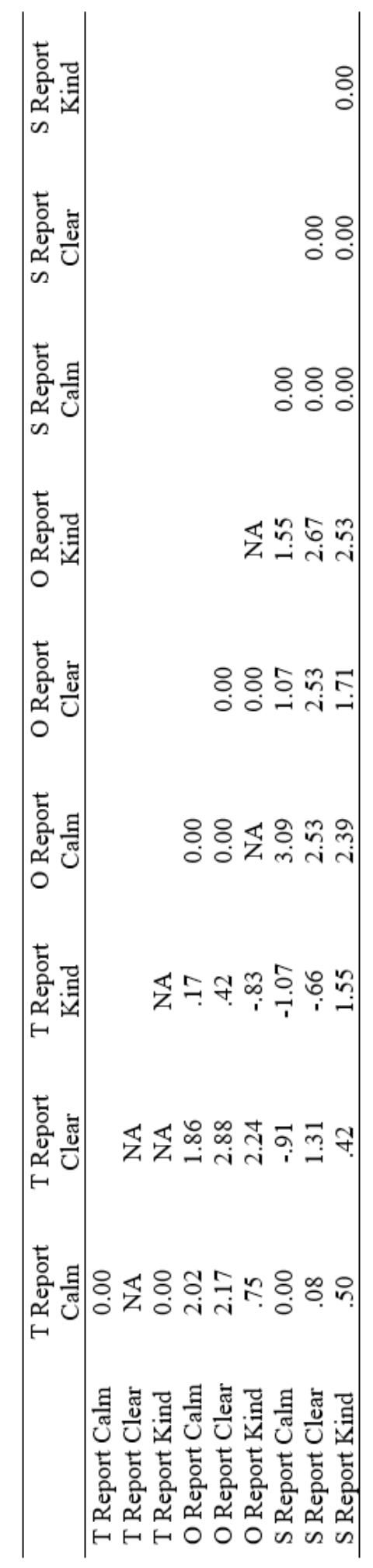


Table 18

MTMI Matrix for Calm, Clear, and Kind from Teacher, Observer, and Student Reports

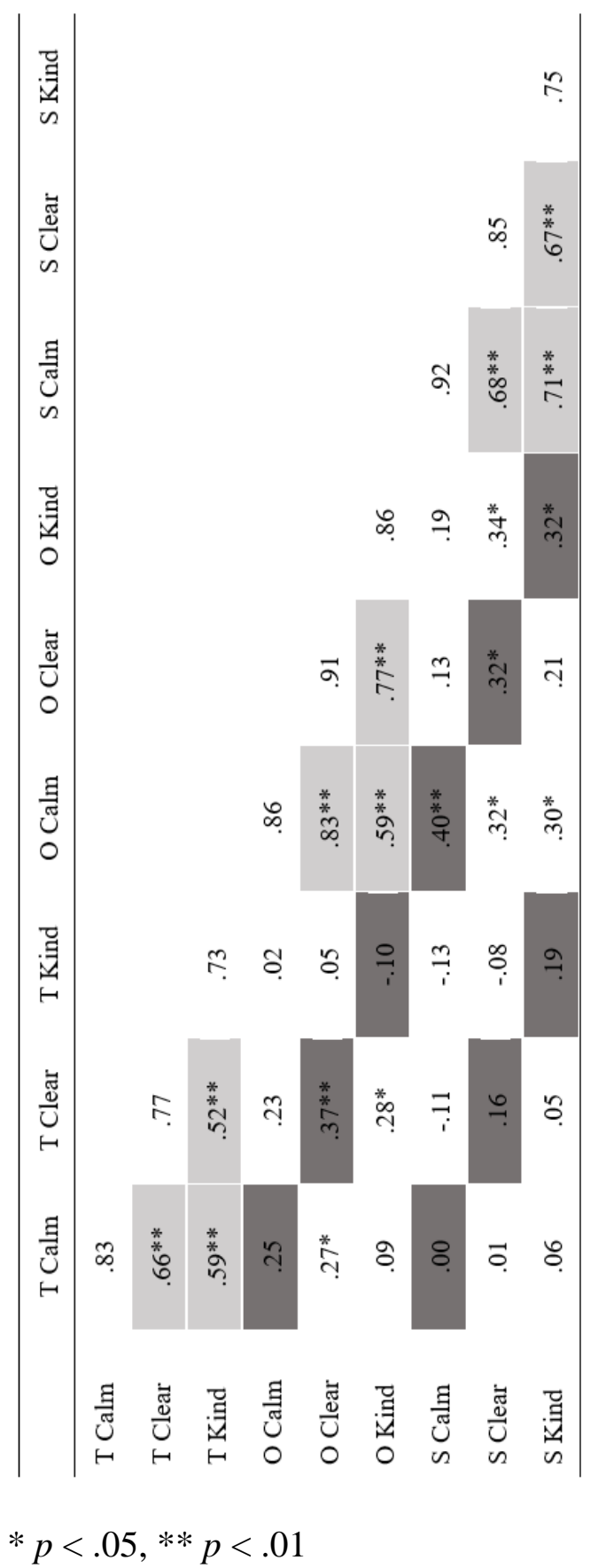

Note. Reliabilities are on the main diagonal. Light gray shadings are within-informant correlations. Dark gray shadings are between-informant correlations (same trait). $N=44-$ 65. 
Table 19

Correlations Between Each Teacher Mindfulness in the Classroom Measure and Teacher Dispositional Mindfulness and Job Stress

\begin{tabular}{lcc}
\hline & $\begin{array}{c}\text { Teacher Dispositional } \\
\text { Mindfulness }\end{array}$ & Teacher Job Stress \\
\hline Teacher Report Calm & $.46^{* *}$ & $-.30^{*}$ \\
Teacher Report Clear & $.47^{* *}$ & $-.26^{*}$ \\
Teacher Report Kind & $.34^{* *}$ & -.21 \\
Observer Report Calm & .14 & -.05 \\
Observer Report Clear & .14 & .04 \\
Observer Report Kind & .13 & .07 \\
Student Report Calm & -.19 & $.30 *$ \\
Student Report Clear & .12 & .14 \\
Student Report Kind & .08 & .20 \\
\hline
\end{tabular}

$* p<.05, * * p<.01$

Note. $N=44-65$. 
Table 20

Regression Analyses Predicting Teacher Reports of Calm, Clear, and Kind

\begin{tabular}{|c|c|c|c|c|c|c|c|c|c|}
\hline & \multicolumn{3}{|c|}{ Teacher Report Calm } & \multicolumn{3}{|c|}{ Teacher Report Clear } & \multicolumn{3}{|c|}{ Teacher Report Kind } \\
\hline & $B$ & $S E B$ & $\beta$ & $B$ & $S E B$ & $\beta$ & $B$ & $S E B$ & $\beta$ \\
\hline $\begin{array}{l}\text { Disp. } \\
\text { Mind }\end{array}$ & .52 & .15 & $.40 * * *$ & .53 & .15 & $.43 * * *$ & .32 & .13 & $.31 *$ \\
\hline Job Stress & -.17 & .11 & -.18 & -.11 & .11 & -.12 & -.09 & .10 & -.11 \\
\hline $\begin{array}{l}\text { Adjusted } \\
R^{2}\end{array}$ & & & .21 & & & .21 & & & .10 \\
\hline Total df & & & 64 & & & 64 & & & 64 \\
\hline
\end{tabular}

Note. $N=65$. 
Table 21

Regression Analyses Predicting Observer Reports of Calm, Clear, and Kind

\begin{tabular}{lccccccccc}
\hline & \multicolumn{3}{c}{ Observer Report Calm } & \multicolumn{3}{c}{ Observer Report Clear } & \multicolumn{3}{c}{ Observer Report Kind } \\
\hline & $B$ & $S E B$ & $\beta$ & $B$ & $S E B$ & $\beta$ & $B$ & $S E B$ & $\beta$ \\
\hline $\begin{array}{l}\text { Disp. } \\
\text { Mind }\end{array}$ & .19 & .20 & .14 & .20 & .16 & .18 & .20 & .17 & .18 \\
Job Stress & .00 & .16 & .00 & .10 & .13 & .11 & .12 & .13 & .13 \\
Adjusted & & & -.02 & & & -.01 & & & .00 \\
$R^{2}$ & & & & & & & & & \\
Total df & & 57 & & & & & & & \\
\hline Note. $N=58$.
\end{tabular}


Table 22

Regression Analyses Predicting Student Reports of Calm, Clear, and Kind

\begin{tabular}{|c|c|c|c|c|c|c|c|c|c|}
\hline & \multicolumn{3}{|c|}{ Student Report Calm } & \multicolumn{3}{|c|}{ Student Report Clear } & \multicolumn{3}{|c|}{ Student Report Kind } \\
\hline & $B$ & $S E B$ & $\beta$ & $B$ & $S E B$ & $\beta$ & $B$ & $S E B$ & $\beta$ \\
\hline $\begin{array}{l}\text { Disp. } \\
\text { Mind }\end{array}$ & -.14 & .19 & -.11 & .16 & .15 & .17 & .14 & .15 & .15 \\
\hline Job Stress & .24 & .14 & .27 & .13 & .11 & .18 & .16 & .11 & .24 \\
\hline $\begin{array}{l}\text { Adjusted } \\
R^{2}\end{array}$ & & & .06 & & & .00 & & & .01 \\
\hline Total df & & & 43 & & & 43 & & & 43 \\
\hline
\end{tabular}


Aikens, K.A., Astin, J., Pelletier, K.R., Levanovich, K., Baase, C.M., Park, Y.Y., \& Bodnar, C.M. (2014). Mindfulness goes to work: Impact of an on-line workplace intervention. Journal of Occupational and Environmental Medicine, 56, 721-731.

Baer, R.A., Smith, G.T., Hopkins, J., Krietemeyer, J., \& Toney, L. (2006). Using selfreport assessment methods to explore facets of mindfulness. Assessment, 13, 2745.

Baer, R.A., Smith, G.T., Lykins, E., Button, D., Krietemeyer, J., Sauer, S., Walsh, E., Duggan, D., \& Williams, J.M.G. (2008). Construct validity of the Five Facet Mindfulness Questionnaire in meditating and nonmeditating samples. Assessment, 15, 329-342.

Brown, K.W., \& Ryan, R.M. (2003). The benefits of being present: Mindfulness and its role in psychological well-being. Journal of Personality and Social Psychology, $84,822-848$.

Campbell, D.T., \& Fiske, D.W. (1959). Convergent and discriminant validation by the multitrait-multimethod matrix. Psychological Bulletin, 56, 81-105.

Castro-Schilo, L., Widaman, K.F., \& Grimm, K.J. (2013). Neglect the structure of multitrait-multimethod data at your peril: Implications for associations with external variables. Structural Equation Modeling, 20, 181-207.

Crain, T., Schonert-Reichl, K. \& Roeser, R.W. (in press). Cultivating teacher mindfulness: Effects of a randomized-controlled trial on work, home, and sleep outcomes. Journal of Occupational Health Psychology. 
Cullen, M., \& Pons, G.B. (2015). The mindfulness-based emotional balance

workbook: An eight-week program for improved emotion regulation and resilience. Oakland, CA: New Harbinger Publications.

Dane, E., \& Brummel, B.J. (2013). Examining workplace mindfulness and its relations to job performance and turnover intention. Human Relations, 67, 105-128.

Davidson, R.J., \& Kaszniak, A.W. (2015). Conceptual and methodological issues in research on mindfulness and meditation. American Psychologist, 70, 581-592.

Dotterer, A.M., \& Lowe, K. (2011). Classroom context, school engagement, and academic achievement in early adolescence. Journal of Youth Adolescence, 40, 1649-1660.

Downer, J.T. (2015). Learning About Teacher-Student Interactions (LATSI). Retrieved from http://curry.virginia.edu/research/centers/castl/project/latsi

Ergas, O. (2015). The deeper teachings of mindfulness-based 'interventions' as a reconstruction of 'education'. Journal of Philosophy of Education, 49, 203-220.

Flook, L., Goldberg, S.B., Pinger, L., Bonus, K., \& Davidson, R.J. (2013). Mindfulness for teachers: A pilot study to assess effects on stress, burnout, and teaching efficacy. Mind, Brain, and Education, 7, 182-195.

Fortney, L., Luchterhand, C., Zakletskaia, L., Zgierska, A., \& Rakel, D. (2013). Abbreviated mindfulness intervention for job satisfaction, quality of life, and compassion in primary care clinicians: A pilot study. Annals of Family Medicine, $11,412-420$.

Frank, J.L., Jennings, P.A., \& Greenberg, M.T. (2016). Validation of the mindfulness in teaching scale. Mindfulness. 
Greenberg, M.T., Jennings, P.A., \& Goodman, B. (2010). The interpersonal mindfulness in teaching scale. University Park, PA: Pennsylvania State University.

Gregory, A., Allen, J.P., Mikami, A.Y., Hafen, C.A., \& Pianta, R.C. (2013). Effects of a professional development program on behavioral engagement of students in middle and high school. Psychology in the Schools, 51, 143-163.

Grossman, P. (2011). Defining mindfulness by how poorly I think I pay attention during everyday awareness and other intractable problems for psychology's (re)invention of mindfulness: Comment on Brown et al. (2011). Psychological Assessment, 23, 1034-1040.

Grossman, P., \& Van Dam, N.T. (2011). Mindfulness, by any other name...: Trials and tribulations of sati in Western psychology and science. Contemporary Buddhism, 12, 219-239.

Hafen, C.A., Hamre, B.K., Allen, J.P., Bell, C.A., Gitomer, D.H., \& Pianta, R.C. (2015). Teaching through interactions in secondary school classrooms: Revisiting the factor structure and practical application of the Classroom Assessment Scoring System-Secondary. Journal of Early Adolescence, 35, 651-680.

Hanley, A., Warner, A., \& Garland, E.L. (2015). Associations between mindfulness, psychological well-being, and subjective well-being with respect to contemplative practice. Journal of Happiness Studies, 16, 1423-1436.

Harms, T., Clifford, R.M., \& Cryer, D. (2014). Early childhood environment rating scale. Teachers College Press. 
Hülscheger, U.R., Alberts, H.J.E.M., Feinholdt, A., \& Lang, J.W.B. (2013). Benefits of mindfulness at work: The role of mindfulness in emotion regulation, emotional exhaustion, and job satisfaction. Journal of Applied Psychology, 98, 310-325.

Jennings, P.A. (2014). Early childhood teachers' well-being, mindfulness, and selfcompassion in relation to classroom quality and attitudes towards challenging students. Mindfulness, 6, 732-743.

Jennings, P.A., Frank, J.L., Snowberg, K.E., Coccia, M.A., \& Greenberg, M.T. (2013). Improving classroom learning environments by Cultivating Awareness and Resilience in Education (CARE): Results of a randomized controlled trial. School Psychology Quarterly, 28, 374-390.

Jennings, P.A., \& Greenberg, M.T. (2009). The prosocial classroom: Teacher social and emotional competence in relation to student and classroom outcomes. Review of educational research, 79, 491-525.

Jennings, P.A., Snowberg, K.E., Coccia, M.A., \& Greenberg, M.T. (2011). Improving classroom learning environments by Cultivating Awareness and Resilience in Education (CARE): Results from two pilot studies. Journal of Classroom Interaction, 46, 37-48.

Kabat-Zinn, J. (1994). Wherever you go, there you are: Mindfulness meditation in everyday life. New York: Hyperion.

Lambert, R.G., McCarthy, C.J., \& Abbott-Shim, M. (2001). Classroom Appraisal of Resources and Demands: School-age version. Atlanta, GA: Head Start Quality Research Center. 
Lutz, A.., Jha, A.P., Dunne, J.D., \& Saron, C.D. (2015). Investigating the phenomenological matrix of mindfulness-related practices from a neurocognitive perspective. American Psychologist, 70, 632-658.

McArdle, J.J. (2009). Latent variable modeling of differences and changes with longitudinal data. Annual Review of Psychology, 60, 577-605.

Mind and Life Institute (2009). Final report of the Mind and Life Educational Research Network. Unpublished manuscript, Boulder, CO.

Moos, R.H., \& Trickett, E.J. (1987). Classroom environment scale manual. Palo Alto, CA: Consulting Psychologists Press.

Mrazek, M.D., Franklin, M.S., Tarchin Phillips, D., Baird, B., \& Schooler, J.W. (2013). Mindfulness training improves working memory capacity and GRE performance while reducing mind wandering. Psychological Science, 24, 776-781.

Neff, K.D. (2003). The development and validation of a scale to measure selfcompassion. Self and Identity, 2, 223-250.

Nezlek, J.B., Holas, P., Rusanowska, M., \& Krejtz, I. (2015). Being present in the moment: Event-level relationships between mindfulness and stress, positivity, and importance. Personality and Individual Differences.

Pianta, R.C., \& Hamre, B.K. (2009). Conceptualization, measurement, and improvement of classroom processes: Standardized observation can leverage capacity. Educational Researcher, 38, 109-119.

Pianta, R.C., La Paro, K.M., Payne, C., Cox, M.J., \& Bradley, R. (2002). The relation of kindergarten classroom environment to teacher, family, and school characteristics and child outcomes. The Elementary School Journal, 102, 225-238. 
Prakash, R.S., Hussain, M.A., \& Schirda, B. (2015). The role of emotion regulation and cognitive control in the association between mindfulness disposition and stress. Psychology and Aging, 30, 160-171.

Reb, J., Narayanan, J., \& Ho, Z.W. (2013). Mindfulness at work: Antecedents and consequences of employee awareness and absent-mindedness. Mindfulness, 6, 111-122.

Reyes, M.R., Brackett, M.A., Rivers, S.E., White, M., \& Salovey, P. (2012). Classroom emotional climate, student engagement, and academic achievement. Journal of Educational Psychology, 104, 700-712.

Rodgers, C.R., \& Raider-Roth, M.B. (2006). Presence in teaching. Teachers and Teaching: Theory and Practice, 12, 265-287.

Roeser, R.W. (2014). The Emergence of Mindfulness-Based Interventions in Educational Settings. In Motivational Interventions (pp. 379-419). Emerald Group Publishing Limited.

Roeser, R.W. (2016a). Processes of teaching, learning and transfer in mindfulness-based interventions (MBIs) for teachers: A contemplative educational perspective. In K. Schonert-Reichl \& R.W. Roeser (Eds.), Handbook of Mindfulness in Education: Theory, Research, Practice and Future Directions. New York: Springer.

Roeser, R.W. (2016b). Mindfulness in students' motivation and learning in school. In K. Wentzel \& D. Miele (Eds.), Handbook on Motivation at School. New York: Taylor \& Francis. 
Roeser, R.W., \& Eccles, J.S. (2015). Mindfulness and compassion in human development: Introduction to the special section. Developmental Psychology, 51, 1-6.

Roeser, R.W., Mashburn, A.J., Skinner, E.A. (2014). Testing the efficacy of mindfulness training for teachers on improving classroom settings for early adolescents. Unpublished manuscript, Portland State University.

Roeser, R.W., Schonert-Reichl, K.A., Jha, A., Cullen, M., Wallace, L., Wilensky, R., Oberle, E., Thomson, K., Taylor, C., \& Harrison, J. (2013). Mindfulness training and reductions in teacher stress and burnout: Results from two randomized, waitlist-control field trials. Journal of Educational Psychology, 105, 787-804.

Roeser, R.W., Skinner, E., Beers, J., \& Jennings, P.A. (2012). Mindfulness training and teachers' professional development: An emerging area of research and practice. Child Development Perspectives, 6, 167-173.

Schoeberlein, D., \& Koffler, T. (2005). Garrison Institute report: Contemplation and education: A survey of programs using contemplative techniques in $\mathrm{K}-12$ educational settings: A mapping report. New York: Garrison Institute.

Shapiro, S.L., Astin, J.A., Bishop, S.R., \& Cordova, M. (2005). Mindfulness-based stress reduction for health care professionals: Results from a randomized trial. International Journal of Stress Management, 12, 164-176.

Short, M.M., Mazmanian, D., Oinonen, K., \& Mushquash, C.J. (2015). Executive function and self-regulation mediate dispositional mindfulness and well-being. Personality and Individual Differences. 
Stipek, D., \& Byler, P. (2005). Early childhood classroom observation measure: Coding manual.

Taylor, C., Harrison, J., Haimovitz, K., Oberle, E., Thomson, K., Schonert-Reichl, K., \& Roeser, R.W. (2016). Examining ways that a mindfulness-based intervention reduces stress in public school teachers: A mixed-methods study. Mindfulness.

Virtanen, T.E., Lerkkanen, M-K, Poikkeus, A-M., \& Kuorelahti, M. (2015). The relationship between classroom quality and students' engagement in secondary school. Educational Psychology, 3, 963-983.

Wang, M-T, \& Eccles, J.S. (2013). School context, achievement motivation, and academic engagement: A longitudinal study of school engagement using a multidimensional perspective. Learning and Instruction, 28, 12-23.

Wang, M-T, \& Eccles, J.S. (2014). Multilevel predictors of math classroom climate: A comparison study of student and teacher perceptions. Journal of Research on Adolescence.

Young, S. (2006). What is mindfulness?. Retrieved from http://www.shinzen.org/Retreat\%20Reading/What\%20is\%20Mindfulness.pdf 
Appendix A.

Literature Review Article Tables

Table A

Summary of Select Studies Examining Mindfulness and Well-Being in Adults

\begin{tabular}{|c|c|c|c|c|}
\hline Study & Sample & Design & Effects & $\begin{array}{l}\text { Measure of } \\
\text { Mindfulness }\end{array}$ \\
\hline $\begin{array}{l}\text { Taylor et } \\
\text { al. } \\
(2016)\end{array}$ & $\begin{array}{l}59 \text { elementary } \\
\text { and secondary } \\
\text { school teachers }\end{array}$ & $\begin{array}{l}\text { randomized } \\
\text { MT }\end{array}$ & $\begin{array}{l}\text { Decreases in occupational } \\
\text { stress and negative } \\
\text { emotions when describing } \\
\text { stressful experiences after } \\
\text { training; increases in affect } \\
\text { words, positive emotion } \\
\text { words, positive feeling } \\
\text { words when describing } \\
\text { challenging students, } \\
\text { efficacy for regulating } \\
\text { emotions, efficacy for } \\
\text { forgiving students, } \\
\text { dispositional forgiveness, } \\
\text { and situational forgiveness } \\
\text { after training }\end{array}$ & N/A \\
\hline $\begin{array}{l}\text { Hanley, } \\
\text { Warner, } \\
\& \\
\text { Garland } \\
(2015)\end{array}$ & $\begin{array}{l}106 \\
\text { contemplative } \\
\text { practitioners } \\
\text { and } 245 \text { non- } \\
\text { practitioners }\end{array}$ & correlational & $\begin{array}{l}\text { People who engage in } \\
\text { contemplative practices } \\
\text { had higher mindfulness, } \\
\text { PWB, and SWB; trait } \\
\text { mindfulness positively } \\
\text { related to PWB and SWB }\end{array}$ & $\begin{array}{l}\text { FFMQ (self- } \\
\text { report) }\end{array}$ \\
\hline $\begin{array}{l}\text { Nezlek } \\
\text { et al. } \\
(2015)\end{array}$ & 153 adults & $\begin{array}{l}\text { event } \\
\text { sampling }\end{array}$ & $\begin{array}{l}\text { Trait mindfulness } \\
\text { positively related to } \\
\text { presence, positivity, and } \\
\text { importance of daily events; } \\
\text { negatively related to stress } \\
\text { of daily events; presence } \\
\text { and stress in daily events } \\
\text { positively related }\end{array}$ & $\begin{array}{l}\text { MAAS } \\
\text { (self-report) }\end{array}$ \\
\hline
\end{tabular}


Table A continued

\begin{tabular}{|c|c|c|c|c|}
\hline Study & Sample & Design & Effects & $\begin{array}{l}\text { Measure of } \\
\text { Mindfulness }\end{array}$ \\
\hline $\begin{array}{l}\text { Prakash, } \\
\text { Hussain, } \\
\& \\
\text { Schirda } \\
(2015)\end{array}$ & $\begin{array}{l}50 \text { older } \\
\text { and } 50 \\
\text { younger } \\
\text { adults }\end{array}$ & correlational & $\begin{array}{l}\text { Trait mindfulness negatively } \\
\text { related to perceived stress and } \\
\text { mediated by increased emotion } \\
\text { regulation }\end{array}$ & $\begin{array}{l}\text { MAAS } \\
\text { (self-report) }\end{array}$ \\
\hline $\begin{array}{l}\text { Short et } \\
\text { al. } \\
(2015)\end{array}$ & $\begin{array}{l}77 \\
\text { undergrads }\end{array}$ & longitudinal & $\begin{array}{l}\text { Trait mindfulness positively } \\
\text { related to self-regulation, self- } \\
\text { monitoring, self-evaluation, self- } \\
\text { reinforcement, and positive } \\
\text { affect; negatively related to } \\
\text { executive dysfunction, behavioral } \\
\text { regulation, metacognition, } \\
\text { negative affect, depression, } \\
\text { anxiety, and stress; self- } \\
\text { regulation mediated relation } \\
\text { between mindfulness and positive } \\
\text { affect; executive function and } \\
\text { self-regulation mediated relation } \\
\text { between mindfulness and } \\
\text { negative affect }\end{array}$ & $\begin{array}{l}\text { FFMQ } \\
\text { (self-report) }\end{array}$ \\
\hline $\begin{array}{l}\text { Aikens } \\
\text { et al. } \\
\text { (2014) }\end{array}$ & $\begin{array}{l}89 \\
\text { employees }\end{array}$ & RCT MT & $\begin{array}{l}\text { Increased mindfulness, resiliency, } \\
\text { and vigor after training; } \\
\text { Decreased perceived stress after } \\
\text { training }\end{array}$ & $\begin{array}{l}\text { FFMQ } \\
\text { (self-report) }\end{array}$ \\
\hline $\begin{array}{l}\text { Jennings } \\
(2014)\end{array}$ & $\begin{array}{l}35 \\
\text { preschool } \\
\text { teachers }\end{array}$ & $\begin{array}{l}\text { baseline } \\
\text { RCT }\end{array}$ & $\begin{array}{l}\text { Trait mindfulness positively } \\
\text { related to emotional support, } \\
\text { perspective-taking, and } \\
\text { sensitivity of discipline }\end{array}$ & $\begin{array}{l}\text { FFMQ } \\
\text { (self-report) }\end{array}$ \\
\hline
\end{tabular}


Table A continued

\begin{tabular}{|c|c|c|c|c|}
\hline Study & Sample & Design & Effects & $\begin{array}{l}\text { Measure of } \\
\text { Mindfulness }\end{array}$ \\
\hline $\begin{array}{l}\text { Dane \& } \\
\text { Brummel } \\
(2013)\end{array}$ & 98 servers & correlational & $\begin{array}{l}\text { Trait mindfulness positively } \\
\text { related to job performance and } \\
\text { negatively to turnover } \\
\text { intention }\end{array}$ & $\begin{array}{l}\text { MAAS } \\
\text { adjusted for } \\
\text { the } \\
\text { workplace } \\
\text { (self-report) }\end{array}$ \\
\hline $\begin{array}{l}\text { Flook et al. } \\
\text { (2013) }\end{array}$ & $\begin{array}{l}18 \\
\text { elementary } \\
\text { school } \\
\text { teachers }\end{array}$ & $\begin{array}{l}\text { randomized } \\
\text { mMBSR }\end{array}$ & $\begin{array}{l}\text { Decreased psychological } \\
\text { symptoms and burnout after } \\
\text { training; increased describe } \\
\text { (FFMQ), self-compassion } \\
\text { humanity, affective attentional } \\
\text { bias, and classroom behavior }\end{array}$ & $\begin{array}{l}\text { FFMQ } \\
\text { (self-report) }\end{array}$ \\
\hline $\begin{array}{l}\text { Fortney et } \\
\text { al. (2013) }\end{array}$ & $\begin{array}{l}30 \text { primary } \\
\text { care } \\
\text { clinicians }\end{array}$ & $\begin{array}{l}\text { non- } \\
\text { randomized } \\
\text { MT }\end{array}$ & $\begin{array}{l}\text { Training decreased burnout, } \\
\text { emotional exhaustion, } \\
\text { depersonalization, depression, } \\
\text { anxiety, stress, and perceived } \\
\text { stress; training increased } \\
\text { personal accomplishment }\end{array}$ & N/A \\
\hline $\begin{array}{l}\text { Hülscheger } \\
\text { et al. } \\
(2013)\end{array}$ & $\begin{array}{l}219 \\
\text { employees; } \\
64 \\
\text { employees }\end{array}$ & $\begin{array}{l}\text { longitudinal; } \\
\text { randomized } \\
\text { self-training } \\
\text { mindfulness }\end{array}$ & $\begin{array}{l}\text { Trait mindfulness negatively } \\
\text { related to emotional } \\
\text { exhaustion and positively } \\
\text { related to job satisfaction, } \\
\text { each of which was mediated } \\
\text { by surface acting; training } \\
\text { negatively related to } \\
\text { emotional exhaustion } \\
\text { (mediated by surface acting) } \\
\text { and positively related to job } \\
\text { satisfaction }\end{array}$ & $\begin{array}{l}\text { MAAS } \\
\text { (self-report) }\end{array}$ \\
\hline
\end{tabular}


Table A continued

\begin{tabular}{|c|c|c|c|c|}
\hline Study & Sample & Design & Effects & $\begin{array}{l}\text { Measure of } \\
\text { Mindfulness }\end{array}$ \\
\hline $\begin{array}{l}\text { Jennings } \\
\text { et al. } \\
(2013)\end{array}$ & $\begin{array}{l}50 \text { public } \\
\text { school } \\
\text { teachers }\end{array}$ & $\begin{array}{l}\text { RCT } \\
\text { CARE }\end{array}$ & $\begin{array}{l}\text { Improvements in reappraisal, } \\
\text { reports of daily physical } \\
\text { symptoms, self-efficacy, } \\
\text { efficacy in student engagement, } \\
\text { efficacy in instruction, general } \\
\text { hurry, personal } \\
\text { accomplishment, observing, } \\
\text { non-reactive, and overall } \\
\text { FFMQ after training }\end{array}$ & $\begin{array}{l}\text { FFMQ (self- } \\
\text { report) }\end{array}$ \\
\hline $\begin{array}{l}\text { Mrazek } \\
\text { et al. } \\
(2013)\end{array}$ & $\begin{array}{l}48 \\
\text { undergrads }\end{array}$ & $\begin{array}{l}\text { randomized } \\
\mathrm{MT}\end{array}$ & $\begin{array}{l}\text { Training increased GRE } \\
\text { reading comprehension scores } \\
\text { and working memory capacity; } \\
\text { decreased mind wandering }\end{array}$ & N/A \\
\hline $\begin{array}{l}\text { Reb et } \\
\text { al. } \\
(2013)\end{array}$ & $\begin{array}{l}231 \\
\text { working } \\
\text { adults }\end{array}$ & longitudinal & $\begin{array}{l}\text { Awareness positively related to } \\
\text { job satisfaction, psychological } \\
\text { need satisfaction, task } \\
\text { performance, and } \\
\text { organizational citizenship } \\
\text { behaviors and negatively with } \\
\text { deviance and emotional } \\
\text { exhaustion }\end{array}$ & $\begin{array}{l}\text { FFMQ (self- } \\
\text { report) }\end{array}$ \\
\hline $\begin{array}{l}\text { Roeser } \\
\text { et al. } \\
(2013)\end{array}$ & $\begin{array}{l}113 \\
\text { elementary } \\
\text { and } \\
\text { secondary } \\
\text { school } \\
\text { teachers }\end{array}$ & $\begin{array}{l}\text { randomized } \\
\mathrm{MT}\end{array}$ & $\begin{array}{l}\text { Increased mindfulness, focused } \\
\text { attention, working memory } \\
\text { capacity, and occupational self- } \\
\text { compassion at follow-up; } \\
\text { decreases occupational stress } \\
\text { and burnout at follow-up }\end{array}$ & $\begin{array}{l}\text { FFMQ (self- } \\
\text { report) }\end{array}$ \\
\hline
\end{tabular}


Table A continued

\begin{tabular}{|c|c|c|c|c|}
\hline Study & Sample & Design & Effects & $\begin{array}{l}\text { Measure of } \\
\text { Mindfulness }\end{array}$ \\
\hline $\begin{array}{l}\text { Jennings et al. } \\
(2011)\end{array}$ & $\begin{array}{l}31 \text { urban } \\
\text { school and } 43 \\
\text { suburban/semi- } \\
\text { rural school } \\
\text { teachers }\end{array}$ & $\begin{array}{l}\text { pilot study } \\
\text { CARE }\end{array}$ & $\begin{array}{l}\text { For urban } \\
\text { sample, } \\
\text { improvements } \\
\text { in well-being } \\
\text { and } \\
\text { mindfulness } \\
\text { and reduced } \\
\text { stress for time } \\
\text { demands }\end{array}$ & $\begin{array}{l}\text { Interpersonal } \\
\text { Mindfulness in } \\
\text { Teaching } \\
\text { Questionnaire } \\
\text { (self-report); } \\
\text { FFMQ (self- } \\
\text { report) }\end{array}$ \\
\hline $\begin{array}{l}\text { Shapiro et al. } \\
(2005)\end{array}$ & $\begin{array}{l}38 \text { health care } \\
\text { professionals }\end{array}$ & RCT MBSR & $\begin{array}{l}\text { Training } \\
\text { decreased } \\
\text { perceived } \\
\text { stress and } \\
\text { increased self- } \\
\text { compassion }\end{array}$ & N/A \\
\hline $\begin{array}{l}\text { Brown \& Ryan } \\
\text { (2003) }\end{array}$ & $\begin{array}{l}\text { undergrads and } \\
\text { adults }\end{array}$ & $\begin{array}{l}\text { correlational, } \\
\text { quasi- } \\
\text { experimental, } \\
\text { and laboratory } \\
\text { studies }\end{array}$ & $\begin{array}{l}\text { Trait } \\
\text { mindfulness } \\
\text { negatively } \\
\text { related to } \\
\text { depression, } \\
\text { angry hostility, } \\
\text { self- } \\
\text { consciousness, } \\
\text { anxiety, } \\
\text { negative } \\
\text { affectivity, } \\
\text { physical } \\
\text { symptoms, and } \\
\text { number of } \\
\text { doctor's visits } \\
\text { over past } 21 \\
\text { days; } \\
\text { positively } \\
\text { related to } \\
\text { positive } \\
\text { affectivity, } \\
\text { emotional } \\
\text { intelligence, } \\
\text { autonomy, } \\
\text { competence, } \\
\text { and relatedness }\end{array}$ & $\begin{array}{l}\text { MAAS (self- } \\
\text { report) }\end{array}$ \\
\hline
\end{tabular}


Table B

Summary of Select Studies Examining Classroom Climates and Student Engagement

\begin{tabular}{|c|c|c|c|c|}
\hline Study & Sample & Design & Effects & $\begin{array}{l}\text { Measure of } \\
\text { Classroom } \\
\text { Climate }\end{array}$ \\
\hline $\begin{array}{l}\text { Virtanen } \\
\text { et al. } \\
(2015)\end{array}$ & $\begin{array}{l}181 \text { Finnish } \\
\text { 7th-9th grade } \\
\text { students }\end{array}$ & correlational & $\begin{array}{l}\text { Classrooms with higher } \\
\text { organization and } \\
\text { instructional support had } \\
\text { students with higher } \\
\text { behavioral engagement; } \\
\text { emotional support } \\
\text { indirectly related to } \\
\text { student engagement } \\
\text { through classroom } \\
\text { organization and } \\
\text { instructional support }\end{array}$ & CLASS-S \\
\hline $\begin{array}{l}\text { Wang \& } \\
\text { Eccles } \\
(2014)\end{array}$ & $\begin{array}{l}29507 \text { th grade } \\
\text { students in } \\
\text { math } \\
\text { classrooms; } \\
132 \text { math } \\
\text { teachers }\end{array}$ & correlational & $\begin{array}{l}\text { Teacher and student } \\
\text { reports agreed on } \\
\text { perceptions of } \\
\text { collaboration promotion } \\
\text { and autonomy support, } \\
\text { but small correlations }\end{array}$ & $\begin{array}{l}\text { Adapted } \\
\text { from } \\
\text { previous } \\
\text { studies } \\
\text { (teacher and } \\
\text { student self- } \\
\text { reports) }\end{array}$ \\
\hline $\begin{array}{l}\text { Gregory } \\
\text { et al. } \\
(2013)\end{array}$ & $\begin{array}{l}87 \text { middle and } \\
\text { high school } \\
\text { teachers; } 1669 \\
\text { middle and } \\
\text { high school } \\
\text { students }\end{array}$ & $\begin{array}{l}\text { RCT My } \\
\text { Teaching } \\
\text { Partner- } \\
\text { Secondary } \\
\text { program } \\
\text { intervention }\end{array}$ & $\begin{array}{l}\text { Participating in training } \\
\text { positively related to } \\
\text { student engagement at } \\
\text { end of year; this relation } \\
\text { fully mediated by } \\
\text { increases in Instructional } \\
\text { Learning Formats and } \\
\text { Analysis and Problem } \\
\text { Solving dimensions }\end{array}$ & CLASS-S \\
\hline
\end{tabular}


Table B continued

\begin{tabular}{|c|c|c|c|c|}
\hline Study & Sample & Design & Effects & $\begin{array}{l}\text { Measure of } \\
\text { Classroom } \\
\text { Climate }\end{array}$ \\
\hline $\begin{array}{l}\text { Wang \& } \\
\text { Eccles } \\
(2013)\end{array}$ & $\begin{array}{l}1157 \\
\text { middle } \\
\text { school } \\
\text { students }\end{array}$ & longitudinal & $\begin{array}{l}\text { Behavioral engagement } \\
\text { predicted by perceptions of } \\
\text { school structure, provision of } \\
\text { choice, and teacher and peer } \\
\text { emotional support; emotional } \\
\text { engagement predicted by } \\
\text { school structure, provision of } \\
\text { choice, teaching for relevance, } \\
\text { and teacher and peer emotional } \\
\text { support; cognitive engagement } \\
\text { predicted by teaching for } \\
\text { relevance and peer emotional } \\
\text { support }\end{array}$ & $\begin{array}{l}\text { School } \\
\text { Environment } \\
\text { Measure (self- } \\
\text { report) }\end{array}$ \\
\hline $\begin{array}{l}\text { Reyes et } \\
\text { al. } \\
(2012)\end{array}$ & $\begin{array}{l}13995 \text { th } \\
\text { and 6th } \\
\text { grade } \\
\text { students }\end{array}$ & correlational & $\begin{array}{l}\text { Classroom emotional climate } \\
\text { positively related to students' } \\
\text { grades and engagement; } \\
\text { student engagement positively } \\
\text { related to grades; engagement } \\
\text { partially mediated relation } \\
\text { between classroom emotional } \\
\text { climate and grades }\end{array}$ & CLASS \\
\hline $\begin{array}{l}\text { Dotterer } \\
\text { \& Lowe } \\
(2011)\end{array}$ & $\begin{array}{l}10145 \text { th } \\
\text { grade } \\
\text { students }\end{array}$ & correlational & $\begin{array}{l}\text { Higher instructional quality, } \\
\text { positive socioemotional } \\
\text { climate, and less student- } \\
\text { teacher conflict positively and } \\
\text { significantly related to } \\
\text { behavior engagement }\end{array}$ & $\begin{array}{l}\text { Classroom } \\
\text { Observation } \\
\text { System-5th } \\
\text { grade; teacher } \\
\text { and student } \\
\text { reports }\end{array}$ \\
\hline
\end{tabular}


Appendix B.

Measures

\section{Teacher Mindfulness in the Classroom:}

* Those items retained for subsequent analyses from the selected item pools.

Teacher Reports:

Calm:

1. When I am upset with my class I can still calmly communicate how I am feeling.*

2. When I am not happy with my class, I calmly talk to students about what I would like to see happen.*

3. If I get angry or unhappy about students' behavior, I step back and try to see what's going on.

4. If I get upset in class, I get over it quickly.*

5. When things go wrong, I bounce back pretty fast.*

Reactive (r):

1. When something bad happens at school, I tend to blow it out of proportion.*

2. When students do something wrong, I tend to over-react.*

3. Once I get angry in class, my temper tends to take over.*

4. When my class upsets me, it takes me a long time to calm down.*

5. When something painful happens at school, I cannot stop thinking about it.*

Clear:

1. When I am in the classroom, I am fully focused on teaching.*

2. When something or someone upsets me in the classroom, I am able to take a balanced view of the situation.*

3. When class is not going well, I can find the right words to explain to students what is happening.*

4. When I am unhappy with a student's behavior, I'm good at finding ways to let him or her know what I am thinking and feeling.*

5. While I am listening to one student, I am still aware of the whole class. Distracted (r):

1. I can get so busy thinking about other things that I am not really listening to my students. *

2. When I am teaching I seem to be running on automatic, without much awareness of what I am doing.*

3. When something or someone upsets me in class, it takes me some time to come to a less emotional, and more rational, perspective on the situation.*

4. When I am upset with students, I have trouble finding the right words to express what I am feeling.*

5. When class is going badly, I find it hard to figure out what is happening.* Kind:

1. When my students are going through a hard time, I try to give them the caring and nurturing they need.* 
2. I try to be understanding and patient towards those aspects of my class I don't always like.*

3. When I am working with students, I think about all the struggles that come with this age.*

4. I feel tender towards my students and all they are dealing with.*

5. When I see a student being treated unfairly, I want to step in.* Critical (r):

1. If students don't listen, I get pretty irritated at them.

2. If I can't get through my whole lesson, I get frustrated.*

3. Sometimes I feel like students are trying to push my buttons.*

4. When students don't understand the material we are covering in class, I assume it's because they did not do their homework.*

5. If students do not do well in my class, they only have themselves to blame.*

6. When dealing with problem students, I often find myself thinking, "What is wrong with you?"*

\section{Student Reports:}

Calm:

1. I can count on this teacher to be in a good mood.*

2. Even when we mess up, our teacher deals with us in a calm and fair way.*

3. No matter what happens in class, our teacher can handle it.*

Reactive (r):

1. My teacher gets annoyed with me.

2. My teacher gets irritated pretty easily.*

3. Some days this teacher is in a good mood, other days - not so much.*

4. If we don't do what we are supposed to, this teacher gets very upset.*

Clear:

1. My teacher treats everyone fairly.*

2. My teacher knows when I need extra help.*

3. My teacher notices when I am confused or not paying attention.* Distracted (r):

1. My teacher just keeps going on with the lesson, whether we are getting it or not.*

2. My teacher often gets off track and we end up missing part of the lesson.*

3. Whether or not students can get away with something depends on how the teacher is feeling that day.*

Kind:

1. My teacher likes me.

2. My teacher says nice things to me.

3. My teacher helps me when I need help.

4. My teacher takes a personal interest in students.*

5. My teacher goes out of his or her way to help students.*

6. I feel like this teacher is on my side.

7. My teacher seems to genuinely like students.*

Critical (r): 
1. My teacher "talks down" to students.*

2. My teacher does not trust students.*

3. Some of the things this teacher says can be pretty harsh.*

Third-Person Reports (behavioral indicators from the CLASS):

Calm:

- Effective redirection of misbehavior*

- Proactive*

- Punitive control (r)*

Clear:

- Maximizing learning time*

- Routines*

- Effectiveness in addressing problems*

- Awareness*

- Clear expectations*

- Preparation*

- Building on student responses*

Kind:

- Encouragement and affirmation*

- Respect*

- Positive communications*

- Responsiveness to needs*

- Positive affect*

- $\quad \operatorname{Disrespect}(\mathrm{r})^{*}$

\section{Teacher Dispositional Mindfulness:}

Non-reactivity:

- I watch my feelings without getting lost in them.

- Usually when I have distressing thoughts or images, I feel calm soon after.

- Usually when I have distressing thoughts or images, I just notice them and let go.

- Usually when I have distressing thoughts or images, I am able to just notice them without reacting.

- Usually when I have distressing thoughts or images, I "step back" and am aware of the thought or image without getting taken over by it.

Describing:

- I'm good at finding the words to describe my feelings.

- I can easily put my beliefs, opinions, and expectations into words.

- It's hard for me to find the words to describe what I'm thinking. (r)

- When I have a sensation in my body, it's difficult for me to describe it because I can't find the right words. (r)

- Even when I am feeling terribly upset, I can find a way to put it into words. Acting with Awareness:

- I find it difficult to stay focused on what's happening in the present. (r)

- I rush through activities without being really attentive to them. (r)

- I do jobs or tasks automatically without being aware of what I'm doing. (r) 
- I find myself doing things without paying attention. (r)

- It seems I am "running on automatic" without much awareness of what I'm doing. (r)

Non-Judgment:

- I tell myself that I shouldn't be feeling the way I'm feeling. (r)

- I make judgments about whether my thoughts are good or bad. (r)

- I tell myself that I shouldn't be thinking the way I'm thinking. (r)

- I think some of my emotions are bad or inappropriate and I shouldn't feel them. (r)

- I disapprove of myself when I have irrational ideas. (r)

Observing:

- I pay attention to sensations, such as the wind in my hair or sun on my face.

- I pay attention to sounds, such as clocks ticking, birds chirping, or cars passing.

- I notice the smells and aromas of things.

- I notice visual elements in art or nature, such as colors, shapes, textures, or patterns of light and shadow.

\section{Teacher Job Stress:}

- I find dealing with student motivational and to be very stressful.

- Having to participate in school activities outside of normal working hours is stressful for me.

- I find trying to be attentive to the needs of fellow teachers is very stressful.

- There is a lot of stress at work just keeping up with changing professional standards.

- Job worries distract me when I am at home.

- Stress at work makes me irritable at home.

- Complying with state, federal, and school rules and policies is very stressful. 